\title{
LATERAL AND POSTERIOR DYNAMIC BENDING OF THE MID-SHAFT FEMUR: FRACTURE RISK CURVES FOR THE ADULT POPULATION
}

\section{ERIC ALLEN KENNEDY}

\author{
Thesis submitted to the Faculty of the \\ Virginia Polytechnic Institute and State University \\ in partial fulfillment of the requirements for the degree of
}

Master of Science

in

Mechanical Engineering

Stefan M. Duma, Ph.D., Chair

Joel D. Stitzel, Ph.D.

Michael L. Madigan, Ph.D.

April 22, 2004

\section{Blacksburg, Virginia}

Keywords: Bone, Dynamic, Femur, Impact, Risk Function

Copyright 2004, Eric A. Kennedy 


\title{
LATERAL AND POSTERIOR DYNAMIC BENDING OF THE MID-SHAFT FEMUR: FRACTURE RISK CURVES FOR THE ADULT POPULATION
}

\author{
Eric Allen Kennedy
}

\begin{abstract}
The purpose of this study was to develop injury risk functions for dynamic bending of the human femur in the lateral-to-medial and posterior-to-anterior loading directions. A total of 45 experiments were performed on human cadaver femurs using a dynamic three-point drop test setup. All 45 tests resulted in mid-shaft femur fractures with comminuted wedge and oblique fractures as the most common fracture patterns. The reaction loads were used to develop the injury criteria given that they represent the inertially compensated bending strength of the femur that is more appropriate for dummy load cell application. In the lateral-to-medial bending tests the peak reaction bending moments were $352 \pm 83 \mathrm{Nm}$. In the posterior-to-anterior bending tests the peak reaction bending moments were $348 \pm 96 \mathrm{Nm}$. Regression analysis was used to identify significant parameters, and parametric survival analysis was used to estimate risk functions. Femur cross-sectional area, area moment of inertia (I), maximum distance to the neutral axis (c), $I / c$, occupant gender, and occupant mass are shown to be significant predictors of fracture tolerance, while no significant difference is shown for loading direction, bone mineral density, leg aspect and age. Risk functions are presented for femur cross-sectional area, $I / c$, and a combined occupant gender and mass. The risk function that utilizes the most highly correlated $\left(\mathrm{R}^{2}=0.77\right)$ and significant $(\mathrm{p}=0.0001)$ variable, cross-sectional area, predicts a 50 percent risk of femur fracture of $240 \mathrm{Nm}, 395 \mathrm{Nm}$, and $562 \mathrm{Nm}$ for equivalent cross-sectional area of the $5^{\text {th }}$ percentile female, $50^{\text {th }}$ percentile male, and $95^{\text {th }}$ percentile male respectively.
\end{abstract}




\section{ACKNOWLEDGEMENTS}

There are so many people who have been instrumental in challenging me and providing me with encouragement during my pursuit of this degree. To my parents, Pat and Ed, I cannot say enough to thank you for your blessings as I returned to school. Growing up with such a close and small family, each of my family members, Jane and Ed, Doris and Joe, Minda and Dan, Nancy and Tina, each taught me in their own way how to choose something that you want out of life and how to strive for it. This degree is a piece of the process of achieving that goal.

My friends all gave me their own version of encouragement, although usually that had little to do with actual encouragement and more to do with dealing with my graduate student salary and lack of free time. To my fellow Terrapins, I miss you all, and don't worry, I have taught all the Hokies to Fear the Turtle! To the friends that I made here at the lab, thank you all so much for your help, it would not have been the experience that it was without each of you. In particular, I need to thank Gail Hansen, a true friend with whom I have shared so many laughs and successes, we started this and finished this together, and I am proud for that. To all of my other friends, everyone that I can't mention, thank you for checking in on me and for your support, you are all never as far away as it seems. For Carol, thank you for somehow managing to put up with my stress and time constraints, for your concern and compassion, but most of all thank you for your encouragement, though it's not over, you have toughed out more than I can ever repay you for. And to Schatzie, the dog, thank you for understanding when you gave up your daily walks for my education. I promise that I will pay you back in biscuits, bones, and a backlog of walks for all of your sacrifices.

Thank you to my committee for each of their individual contributions to this master's thesis. First, my thanks to Stefan Duma, who has built the successful program of which I am proud to be a part, and who has provided excellent academic support and guidance over the past two years. To Joel Stitzel, a good friend, who mentored me when I joined the lab and who continues to help me answer my technical challenges. Also, thanks to Michael Madigan who teaches an excellent biomechanics class and is always willing to spend some extra time with students to lead them to the right answers.

I would like to dedicate this manuscript to the memory of my grandmother, Doris Heagy. Beyond all else, she taught me that the best thing you can do with your life is to go out of your way for others. I hope that I have learned that lesson well. 


\section{TABLE OF CONTENTS}

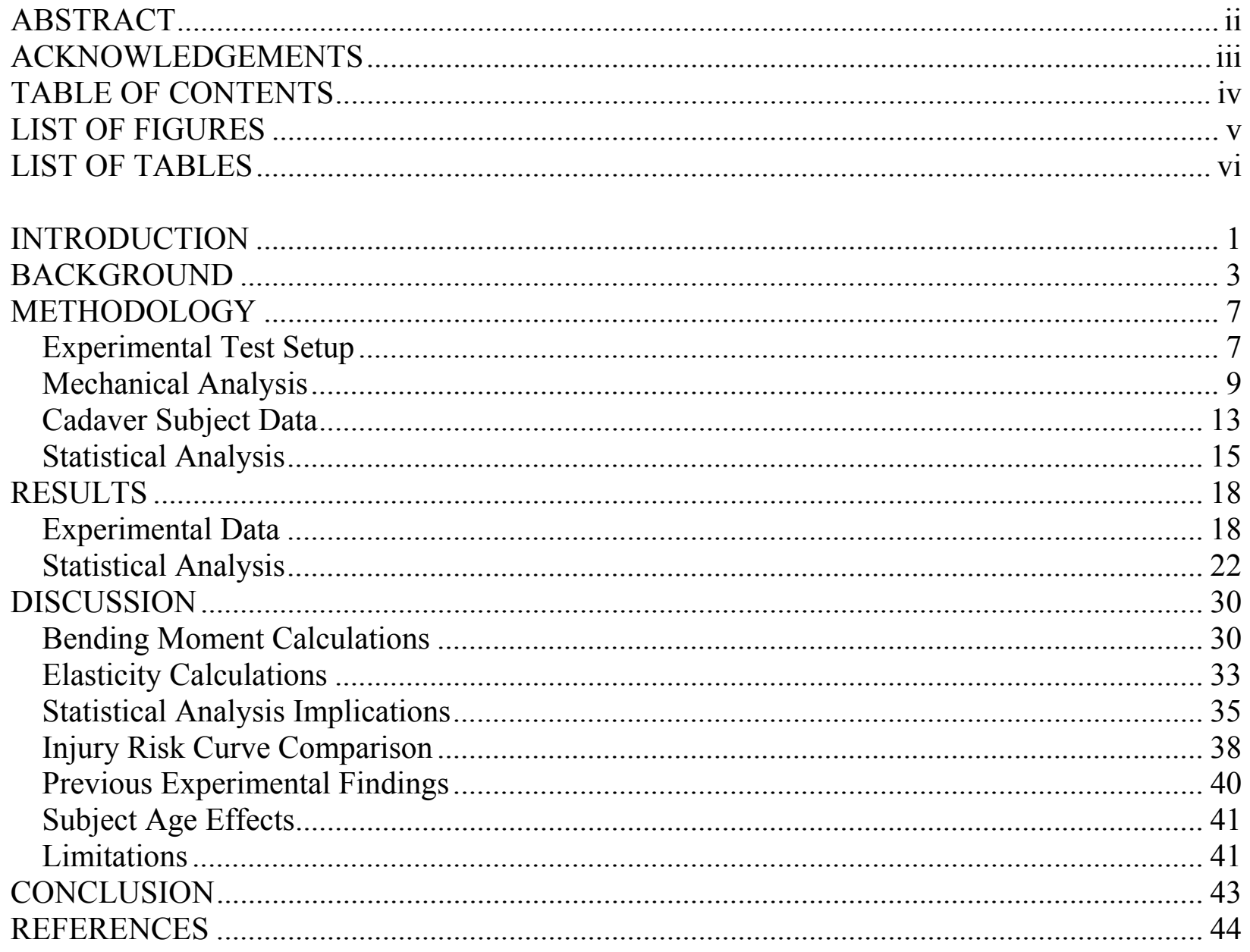

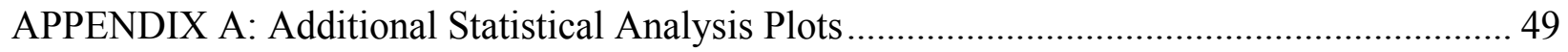

APPENDIX B: Additional Statistical Analysis Plots ……........................................................ 50

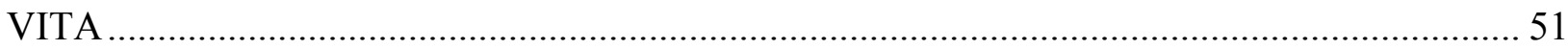




\section{LIST OF FIGURES}

Figure 1: Test apparatus used for femur impact testing. 8

Figure 2: Free-body diagram of measured loads and linear and rotational inertial terms during the impact event. 10

Figure 3: Free-body diagram of sectioned femur, including measured loads and linear and rotational inertial terms during impact event.

Figure 4: Calculated bending moments from reaction and impactor load cells (left axis) and microstrain from strain gage on test specimen (right axis) from test number L6.

Figure 5: Calculated bending moments from reaction and impactor load cells (left axis) and microstrain from strain gage on test specimen (right axis) from test number L7 ................ 21

Figure 6: Stress-strain curve used for determination of elastic modulus of femur....................... 22

Figure 7: Bending moment vs. cross-sectional area. .............................................................. 24

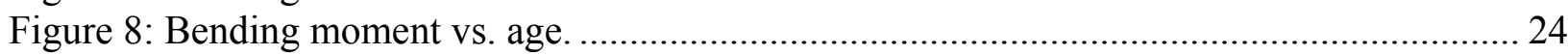

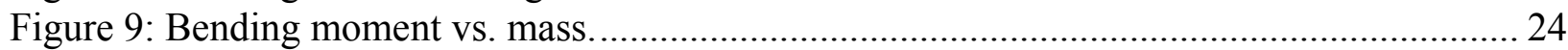

Figure 10: Bending moment vs. bone mineral density. .......................................................... 24

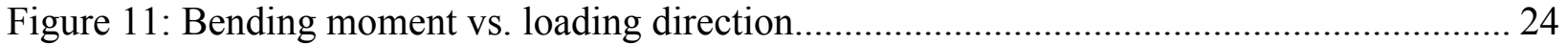

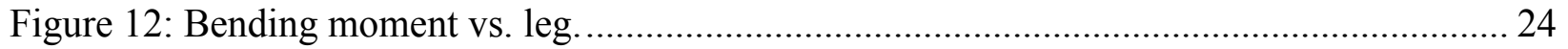

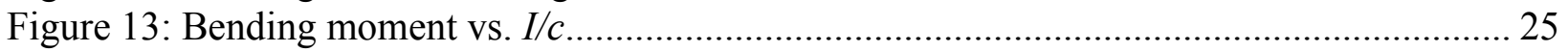

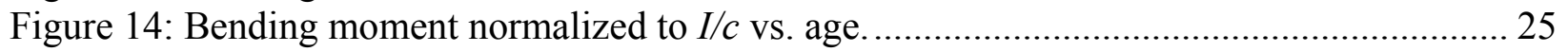

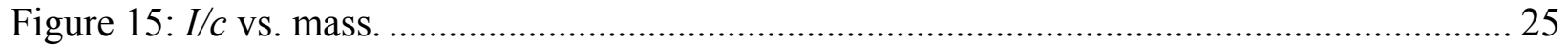

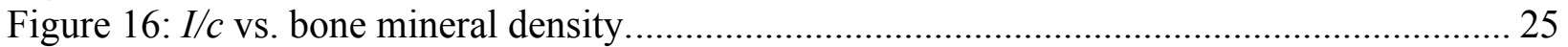

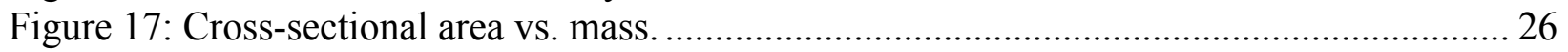

Figure 18: Cross-sectional area vs. bone mineral density......................................................... 26

Figure 19: Femur fracture risk curves based on moment and mid-shaft femur cross-sectional area, geometric variable area is estimated by empirical distribution of specimen data....... 28

Figure 20: Example of inertial effects present in measured impactor load from test number L6. 31

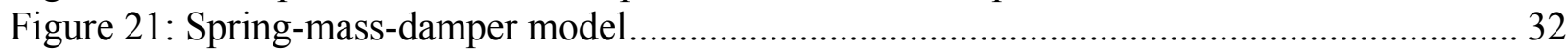

Figure 22: Verification of suitability of Weibull model to explain experimental data.................. 36 


\section{LIST OF TABLES}

Table 1: Previous research on bending tolerance of human femurs. .................................... 4

Table 2: Cadaver subject information for lateral bending tests. ............................................ 14

Table 3: Cadaver subject information for posterior bending tests....................................... 15

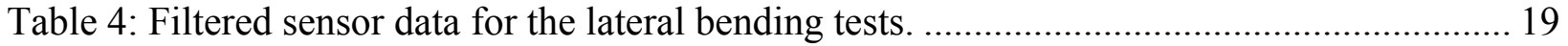

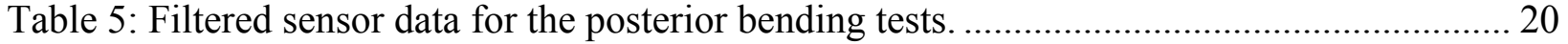

Table 6: Results from the regression analysis on factors related to peak reaction moment........ 23

Table 7: Pearson correlation coefficients for peak moment and other variables...................... 23

Table 8: Percentile estimates of cross-sectional area and $I / c$ based on specimen data................ 26

Table 9: Model parameters, test statistics and p-values for significance of models containing single variables; the test of significance is based on the bootstrap analysis..................... 27

Table 10: 50 percent risk of femur fracture due to injury risk curves using variables of area, $I / c$,

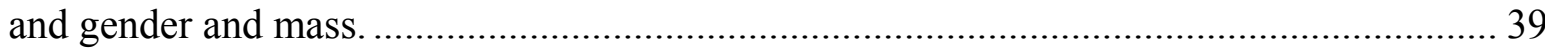




\section{INTRODUCTION}

Femur fractures, as part of the knee-thigh-hip (KTH) complex, are observed for occupants in automobile collisions as well as pedestrian impacts. Rupp et al. performed a survey of the National Automotive Sampling System (NASS) and found that approximately 30,000 occupants sustain injuries to the KTH complex each year with an AIS of 2+ (2002). The rate of injury to lower limbs in a car accident has been shown to be higher than all other body regions, except for the head, as the body region most commonly injured during an automobile collision (Pattimore et al. 1991). These lower limb injuries comprise 20 percent to 30 percent of the moderate to severe injuries incurred by an automobile occupant during a collision (Morgan et al. 1991, Dischinger et al. 1994). While femur fractures are generally not life threatening and do not usually result in long term disability, fractures of the femur are classified with an AIS score of 3, being considered a severe injury (AAAM 1990).

Currently, there is no criterion for maximum bending moment of the femur in Federal Motor Vehicle Safety Standard 208 (FMVSS 208). The only criterion currently used in FMVSS 208 to assess the risk of femur fracture is a maximum $10,000 \mathrm{~N}$ axial load. In the year 2001, 4,882 pedestrians were killed in the United States alone, and a total of 78,000 people were injured as a result of a vehicle striking a pedestrian (NHTSA 2001). In these pedestrian impacts, the lower limb is particularly vulnerable. Lower limb injuries constitute approximately 30 percent to 40 percent of all injuries in pedestrian impacts (Isenberg et al. 1996, Sakurai et al. 1994, van Rooij et al. 2003). Due to domestic improvements in driver education and transportation infrastructure, accidents involving pedestrians are on the decline in the U.S.; however, they are on the rise globally, making pedestrian impacts a growing area of concern for automobile safety. Considering the number of scenarios that could induce fracture of the femur 
by bending, a need for evaluation of this injury risk has been demonstrated. However, without adequate injury criteria for dynamic bending of the femur, no evaluation can be made as to the risk that these scenarios present to occupants of varying genders and sizes.

To address the growing issue of pedestrian injuries, the European Enhanced VehicleSafety Committee (EEVC) has adopted standards for maximum femur bending moment in a pedestrian impact test (EEVC 2002). However, there are currently several limitations on the determination of the femur tolerance set forth in this standard. The criterion was scaled via a dynamic multiplier against existing quasistatic femur bending tolerance data (Messerer 1880) to yield a maximum bending moment of $524 \mathrm{Nm}$. This was then scaled to the size of the EEVC legform tester offering a maximum bending moment of $357 \mathrm{Nm}$. Citing that injuries observed to the femur in crash reconstructions are relatively low, this value was then reduced to $300 \mathrm{Nm}$ as a final ruling. This $300 \mathrm{Nm}$ value is applicable to the EEVC pedestrian upper legform impactor, which is approximately the size of a $50^{\text {th }}$ percentile male Anthropomorphic Test Device (ATD) legform (EEVC 2002, SAE 1989). No other anthropometric sizes or gender differences are accounted for in this standard. Despite the fact that this standard begins to address the issue of pedestrian impacts, it is not based on dynamic, direct bending of the human femur and does not account for differences in the bending tolerance for different segments of the population. 


\section{BACKGROUND}

Many studies have been previously performed to determine material properties of human femurs (Table 1). Most of the previous femur tests have been performed on femurs using quasistatic loading rates which are limited, due to the viscoelastic behavior of bone, with respect to predicting femur fracture in automotive accidents (Weber 1859, Messerer 1880, Motoshima 1960, Mather 1967, Mather 1968a, Mather 1968b, Cristofolini et al. 1995, Stromsoe et al. 1995). In addition, the sample populations for the Weber and Messerer data do not represent the current driving population. For these reasons, data from these quasistatic tests are not applicable to the current study of femur injuries in automotive accident scenarios.

Dynamic testing of human femurs was performed by Motoshima (1960), Mather (1968), Martens et al. (1986), Kress and Porta (2001), Kerrigan et al. (2003), and Matsui et al. (2004). In addition to quasistatic testing, Motoshima also conducted impact-bending tests on femurs, and obtained the impact energies using a Charpy impact tester (1960). No ultimate bending moment was recorded for these tests. Similarly, Mather (1968a, 1968b) performed dynamic bending tests on human femurs using a drop tower and also reported the impact energy absorbed by the femur, but not the observed bending moment at fracture. Since the total energy absorbed to failure cannot be directly translated to the bending moment at failure, these data are limited in their ability to predict the ultimate fracture tolerance of the femur (McElhaney et al. 1976). 
Table 1: Previous research on bending tolerance of human femurs.

\begin{tabular}{|c|c|c|c|}
\hline Author & Rate & Female & Male \\
\hline Weber (1859) & Quasistatic & $\begin{array}{c}182 \mathrm{Nm} \\
\text { (Range Unknown) }\end{array}$ & $\begin{array}{c}233 \mathrm{Nm} \\
\text { (Range Unknown) }\end{array}$ \\
\hline Messerer (1880) & Quasistatic & $\begin{array}{c}180 \mathrm{Nm} \\
\text { (Range Unknown) }\end{array}$ & $\begin{array}{c}310 \mathrm{Nm} \\
\text { (Range Unknown) }\end{array}$ \\
\hline Motoshima (1960) & Quasistatic & \multicolumn{2}{|c|}{$\begin{array}{c}165.4 \mathrm{Nm} \\
(144.2 \mathrm{Nm}-183.3 \mathrm{Nm})\end{array}$} \\
\hline Mather (1967) & Quasistatic & \multicolumn{2}{|c|}{$\begin{array}{c}2867 \mathrm{~N}^{*} \\
\text { (Range Unknown) }\end{array}$} \\
\hline Mather (1968) & Quasistatic & \multicolumn{2}{|c|}{$28.7 \mathrm{~J}^{*}$} \\
\hline Cristofolini (1995) & Quasistatic & \multicolumn{2}{|c|}{$\begin{array}{c}34.1 \mathrm{Nm} \\
\text { (Sub-fracture) }\end{array}$} \\
\hline Stromsoe (1995) & Quasistatic & \multicolumn{2}{|c|}{$\begin{array}{c}180.8 \mathrm{Nm} \\
(52.5 \mathrm{Nm}-300 \mathrm{Nm})\end{array}$} \\
\hline Motoshima (1960) & $\begin{array}{c}\text { Dynamic } \\
\text { (Rate Unknown) }\end{array}$ & $\begin{array}{c}40.3 \pm 1.8 \mathrm{~J}^{*} \\
(60-79 \text { year olds })^{* *}\end{array}$ & $\begin{array}{l}\text { Estimated } 49.0 \mathrm{~J} * \\
(20-39 \text { year olds)** }\end{array}$ \\
\hline Martens (1986) & $\begin{array}{c}\text { Dynamic } \\
(<200 \text { ms event })\end{array}$ & \multicolumn{2}{|c|}{$373 \pm 84 \mathrm{Nm}$} \\
\hline Kerrigan (2003) & $\begin{array}{l}\text { Dynamic } \\
(1.2 \mathrm{~m} / \mathrm{s})\end{array}$ & \multicolumn{2}{|c|}{$412 \pm 114 \mathrm{Nm}$} \\
\hline Mather (1968) & $\begin{array}{l}\text { Dynamic } \\
(10.0 \mathrm{~m} / \mathrm{s})\end{array}$ & \multicolumn{2}{|c|}{$42.5 \mathrm{~J}^{*}$} \\
\hline Kress (2001) & $\begin{array}{l}\text { Dynamic } \\
(7.3 \mathrm{~m} / \mathrm{s})\end{array}$ & $\begin{array}{c}5,190 \pm 980 \mathrm{~N}^{*} \\
(3,960 \mathrm{~N}-6,740 \mathrm{~N})\end{array}$ & $\begin{array}{c}7,290 \pm 1,900 \mathrm{~N}^{*} \\
(4,610 \mathrm{~N}-8,960 \mathrm{~N})\end{array}$ \\
\hline Matsui (2004) & $\begin{array}{l}\text { Dynamic } \\
(9.7 \mathrm{~m} / \mathrm{s})\end{array}$ & $\begin{array}{l}9,036 \pm 1,343 \mathrm{~N} * * * \\
\text { (Sub-fracture) }\end{array}$ & $\begin{array}{l}9,350 \pm 1,412 \mathrm{~N}^{* * *} \\
\text { (Fracture) }\end{array}$ \\
\hline
\end{tabular}

* Unknown data for calculating bending moment

** Both females and males within each age range

*** Tests on full-body cadavers, intact thigh, one female in the fracture group, no females in the sub-fracture group

In 1986, Martens et al. performed dynamic loading tests on 33 (26 male and 7 female) cadaveric femurs. The mean age was 64 years, with a range of 47 to 83 years. The bending load was applied by a four-point bending configuration to eliminate the applied shear and compressive forces at the point of the maximum moment. The mean bending moment at fracture was $373 \pm 84 \mathrm{Nm}$; however, the loading rate was given as less than $200 \mathrm{~ms}$, an order of 
magnitude less than needed for automobile crash events. Kress and Porta conducted a parametric study to characterize the response and injuries of simulated pedestrian impacts (2001). The study utilized 604 human cadaver legs and long bones, which were tested using five different methodologies. Femur fractures were studied in a comparison between lateral and anterior impacts of the thigh. The thighs were tested in pairs, one loaded in the anterior direction and one in the lateral direction with the thigh tissue remaining intact. The peak-recorded forces ranged from $3,960 \mathrm{~N}$ to $8,960 \mathrm{~N}$ at an impact velocity of $7.3 \mathrm{~m} / \mathrm{s}$. Kerrigan et al. (2004) conducted three-point bending of eight human femurs and reported an average bending moment of $412 \pm 114 \mathrm{Nm}$. Of these eight tests, seven were conducted without the surrounding tissue intact and impact areas were varied between the distal third, the mid-diaphysis, and the proximal third of the femur.

Lateral impact tests have also been performed on the mid-shaft area of thighs of completely intact cadavers (Matsui et al. 2004). In the tests that resulted in mid-shaft femur fracture, the average impactor load was $9,350 \pm 1,412 \mathrm{~N}$. The average impactor load in subfracture tests was $9,036 \pm 1,343 \mathrm{~N}$. Data is not presented to calculate bending moment; however, fractures were observed to be wedge or incomplete wedge-type fractures, likely indicating the failure of the femur due to bending (Levine 2002).

In summary, the previous research on femur fracture tolerances from bending is limited due to one or more of the following factors: the rate of the applied load, the number of test subjects, the availability of geometric and other data that was measured during the experimentation, analysis of the reaction loads, and the lack of data in varying loading orientations. Additionally, none of the previous studies have developed continuous risk functions or developed statistical relationships between parameters such as gender, mass and 
maximum bending moment that can be utilized in predicting femur fracture. Therefore, the purpose of the current study is to evaluate the response of the human femur to dynamic threepoint bending in order to develop injury risk functions useful for lateral or posterior loading applications. An additional goal of this study is to investigate the differences between the measured loads at the impactor and reaction supports. 


\section{METHODOLOGY}

\section{Experimental Test Setup}

A vertical drop tower was used to evaluate the fracture strength of cadaveric femurs under dynamic loading for both lateral-to-medial (lateral) and posterior-to-anterior (posterior) impacts (Figure 1). The apparatus allowed for the femurs to be loaded in a dynamic three-point bending configuration. The impactor assembly had a total mass of $9.8 \mathrm{~kg}$ and was dropped from a height of $2.17 \mathrm{~m}$ resulting in an impact velocity of $5 \mathrm{~m} / \mathrm{s}$ for each test. The impactor assembly traveled on four reciprocating roller bearings that were attached to two linear shafts in order to minimize lateral flexibility. An impactor load cell (Denton 1968, 22,240 N, Rochester Hills, MI) was used to measure the loads exerted onto the specimen by the impactor. The blade of the impactor was rounded to a $35 \mathrm{~mm}$ diameter head. An accelerometer (Endevco 7264B, $2000 \mathrm{G}$, San Juan Capistrano, CA) was attached to the impactor blade to facilitate inertial compensation of the mass between the femur and active axis of the load cell.

Each femur was disarticulated at the knee and hip joint. The soft tissue was removed from the distal and proximal femur to insure that it would not interfere with the potting technique. To prevent the femur from rotating out of the desired test direction, the exposed ends were potted (Bondo Corporation, Body Filler, Atlanta, GA) in rigid, rectangular mounts. In order to minimize the size and mass of the mounts, some hard tissue was removed using a bone saw to insure a proper fit of the bone into the metal potting box. These pots were then clamped to semicircular roller supports. The purpose of these rollers was to ensure loading in the posterior-to-anterior or lateral-to-medial direction, while maintaining the desired end conditions. 


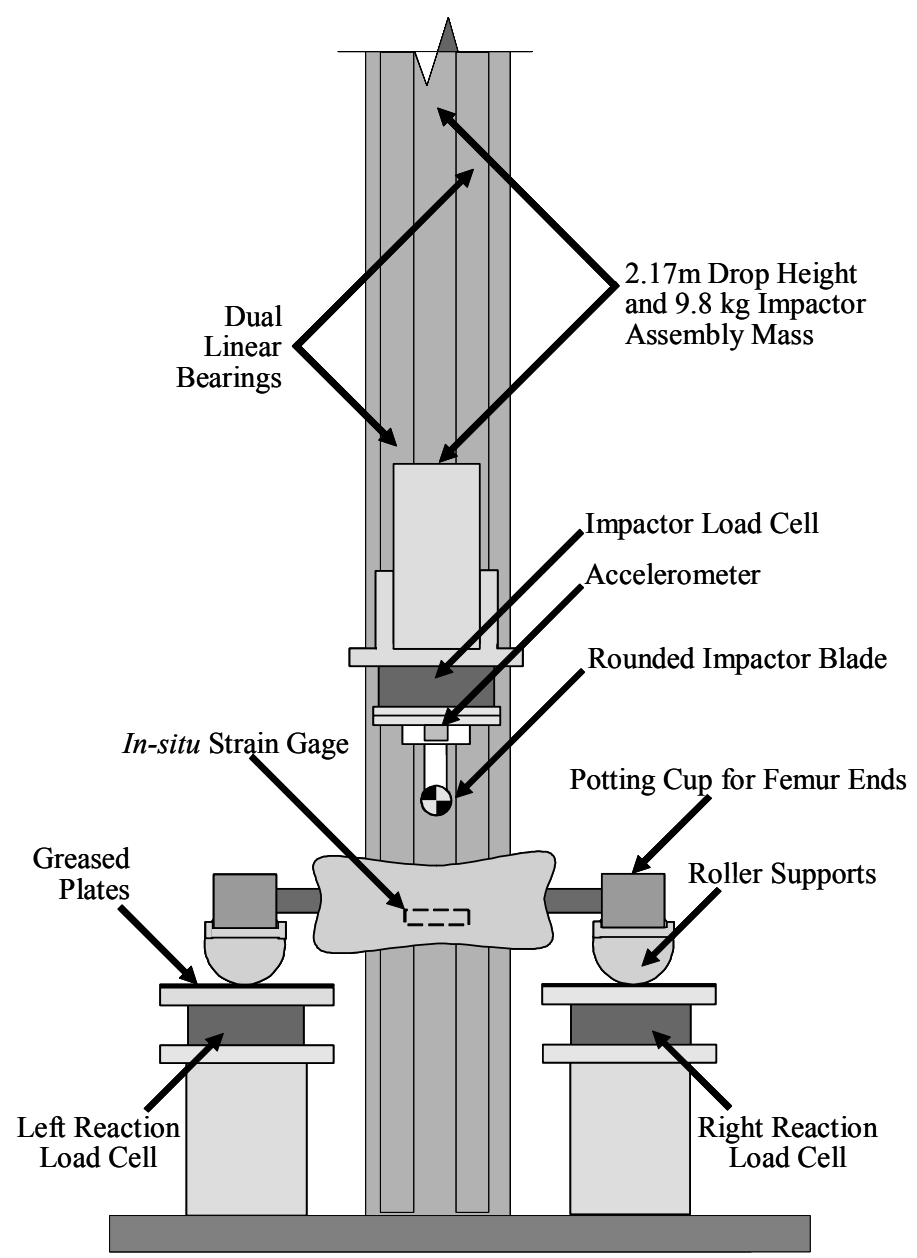

Figure 1: Test apparatus used for femur impact testing.

Each femur was instrumented with a strain gage (Vishay Measurements Group, CEA-06062UW-350, Raleigh, NC) prior to testing. The strain gage was positioned in the middle of the femur on the side opposite of the impact and provided the strain rate and the peak tensile strain until fracture (Fritton and Rubin 2001). The location of the strain gage and geometric dimensions of the femur were recorded prior to testing.

Once prepared for testing, the rollers at each end of the femur were set on corresponding reaction plates. The reaction plates were coated with a small layer of grease to reduce the rolling friction and to minimize the development of shear loading between the rollers and the reaction 
plates during impact. Each reaction plate was supported by a single reaction load cell (Denton $5768,11,120$ N, Rochester Hills, MI) that measured the loads exerted by each end of the femur. The distance between the reaction plates was adjustable to accommodate the various lengths of the femurs used during the test series. The distance between the contact points of the rollers with the plates was recorded for each test as the span length.

During the impact, the impactor blade contacted a trigger strip that was secured to the top of the femur in order to activate the data acquisition for each test. This set the zero time for the data acquisition and video to be at the moment of skin contact. Data from the load cells, accelerometers and strain gage were recorded at a sampling frequency of $30,000 \mathrm{~Hz}$ with an Analog-to-Digital conversion resolution of 16 bits using an Iotech Wavebook with WBK16 strain gage modules (Iotech WBK16, Cleveland, OH). The kinematic behavior of the impactor and femur were recorded using high speed color video at a rate of 3,000 frames per second (Vision Research, Phantom IV, Wayne, NJ). All channels except for the strain gage were filtered to CFC 1000 as per SAE J211. Quantitative Computed Tomography (QCT) (Norlend/Stratec, XCT3000A, Pforzheim, Germany) was performed to determine the bone mineral density and geometric properties, such as area moment of inertia and cross-sectional area, of the cortical bone of the femurs at the mid-shaft location.

\section{Mechanical Analysis}

A free-body diagram illustrates the 3-point bending configuration of the femur and the layout of the impactor and reaction loads from the three load cells (Figure 2). D'Alembert's method illustrates that the difference between the impactor force and the sum of the reaction forces is an inertial term $(m a)$, which represents the inertia from the linear acceleration of the 
effective mass of the femur during the impact event (Equation 1). A rotational inertial term $(I \alpha)$ is also shown, as it influences the moment calculation used to determine the bending moment of the femur.

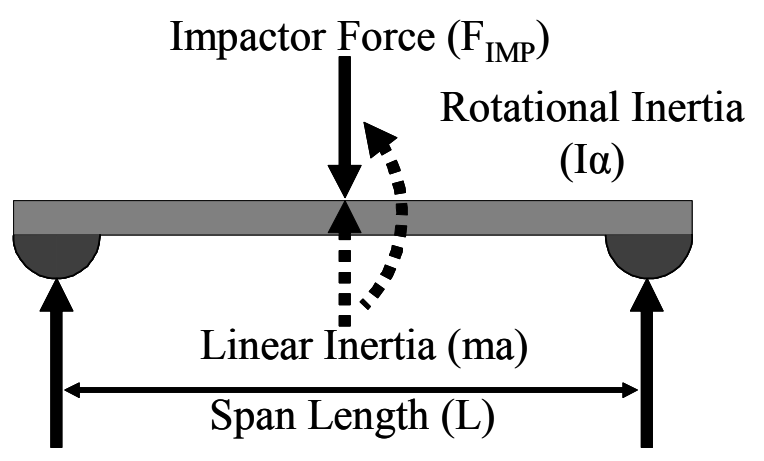

\section{Left Reaction Force $\left(\mathrm{F}_{\mathrm{LR}}\right) \quad$ Right Reaction Force $\left(\mathrm{F}_{\mathrm{RR}}\right)$}

Figure 2: Free-body diagram of measured loads and linear and rotational inertial terms during the impact event.

$$
\text { Impactor Force }\left(F_{I M P}\right)=F_{L R}+F_{R R}+m a
$$

Determination of the mid-shaft bending moment of the femur leads to a new free-body diagram (Figure 3). This diagram sections the femur a very small distance $(\Delta \mathrm{X})$ to the right of the impactor load and the bending moment is calculated based on Equation 2. In this equation, $m_{L}$ is the effective mass of the left half of the femur and $a_{L}$ is the linear acceleration that the left half of the femur is experiencing. The distance, $D$, is the from the left reaction force to the center-of-gravity of the left half of the femur. The values of $I_{L}$ and $\alpha_{L}$ are the mass moment of inertia of the left half of the femur and the angular acceleration of the left half of the femur, respectively. 


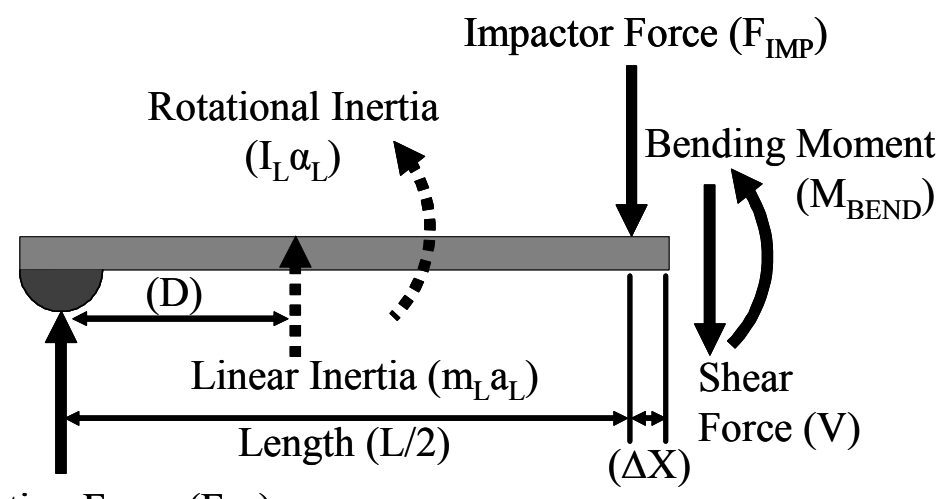

Left Reaction Force $\left(\mathrm{F}_{\mathrm{LR}}\right)$

Figure 3: Free-body diagram of sectioned femur, including measured loads and linear and rotational inertial terms during impact event.

Bending Moment $\left(M_{B E N D}\right)=F_{L R}\left(\frac{L}{2}+\Delta X\right)+m_{L} a_{L}\left(\frac{L}{2}-D+\Delta X\right)-I_{L} \alpha_{L}-F_{I M P}(\Delta X)$

Given the available experimental data, solving for the $m_{L}, a_{L}, D, I_{L}$, and $\alpha_{L}$ terms is not possible; therefore, Equation 2 cannot be solved without additional data or assumptions. However, the effective mid-shaft bending moment of the femur can be calculated using Equation 1 and assuming standard beam theory. Using this approach, two coupled equations are developed to calculate the bending moment as determined by the impactor load cell and the reaction load cells without requiring that the inertial effects be solved for independently. Bending moments from the loads measured by the impactor load cell $\left(M_{I}\right)$ are calculated as shown in Equation 3. Bending moments from the loads measured by the two reaction load cells $\left(M_{R}\right)$ are calculated as shown in Equation 4. In these equations, the load cell forces, $F_{I M P}, F_{L R}$, and $F_{R R}$, are expressed in Newtons, while the span length, $L$, is expressed in meters.

Bending Moment From Impactor Load $\left(M_{I}\right)=\left(\frac{F_{I M P}}{2}\right)\left(\frac{L}{2}\right)=\left(\frac{F_{L R}+F_{R R}+m a}{2}\right)\left(\frac{L}{2}\right)$
Bending Moment From Reaction Loads $\left(M_{R}\right)=\left(\frac{F_{L R}+F_{R R}}{2}\right)\left(\frac{L}{2}\right)=\left(\frac{F_{I M P}-m a}{2}\right)\left(\frac{L}{2}\right)$ 
It can be seen that the $M_{B E N D}$ is the exact mid-shaft bending moment. $M_{I}$ will overestimate the bending moment due to the effect of the inertial term ( $m a$ ) resulting in an overestimate of the actual bending moment. The inertial term $(m a)$ results in $M_{R}$ underestimating the actual bending moment $\left(M_{B E N D}\right)$ but offers a more conservative estimate of bending moment by not over-predicting the actual mid-shaft failure moment (Equation 5).

$$
M_{R}<M_{B E N D}<M_{I}
$$

Given the geometric properties of the femurs available from the QCT scan, beam theory is used to calculate stress within the femur assuming linear elasticity. The peak stress is calculated according to Equation 6. In this equation, $M_{R}$ is the moment calculated from the reaction load cells, and $c$ and $I$ are obtained from the QCT scan. The variables $c$ and $I$ are, the maximum distance to the neutral axis of the femur, and the area moment of inertia of the femur, respectively. The variable $c$ is in meters and $I$ is expressed in meters ${ }^{4}$.

$$
\operatorname{Maximum} \operatorname{Stress}(\sigma)=\frac{M_{R} c}{I}
$$

With the availability of stress and strain data, the modulus of elasticity of the femur is calculated from Equation 7. For consistency, a uniform procedure is used to calculate the modulus of elasticity (Van Ee et al. 1998, Duma et al. 1998, Duma et al. 1999). Data points used from the stress-strain plot for calculations are from approximately 0 percent to 75 percent of the maximum stress observed for each test.

$$
\text { Modulus of Elasticity }(\mathrm{E})=\frac{\Delta \sigma}{\Delta \varepsilon}
$$




\section{Cadaver Subject Data}

A total of 45 fresh frozen cadaveric femurs were obtained from 29 subjects (17 male and 12 female) with an average age of $65 \pm 7$ years and an average body mass of $77.3 \pm 19.8 \mathrm{~kg}$. The average bone mineral density is $1098 \pm 62 \mathrm{mg} / \mathrm{cm}^{3}$, with a range of 968 to $1239 \mathrm{mg} / \mathrm{cm}^{3}$ (Table 2 and Table 3). In the lateral bending tests, the moment of inertia is $27,850 \pm 12,520 \mathrm{~mm}^{4}$ and in the posterior bending tests, the moment of inertia is $31,650 \pm 13,910 \mathrm{~mm}^{4}$. Cross-sectional area is found to be $415 \pm 104 \mathrm{~mm}^{2}$ in the lateral tests and $416 \pm 100 \mathrm{~mm}^{2}$ for the posterior tests. Data listed for the bone mineral density, cross-sectional area and moment of inertia were taken by QCT from the mid-shaft cortical bone of the femur. All test procedures were reviewed and approved by the Virginia Tech Institutional Review Board. 
Table 2: Cadaver subject information for lateral bending tests.

\begin{tabular}{|c|c|c|c|c|c|c|c|c|}
\hline $\begin{array}{c}\text { Test } \\
\text { Number }\end{array}$ & $\begin{array}{l}\text { Subject } \\
\text { Number }\end{array}$ & Gender & \begin{tabular}{|l} 
Age \\
(years)
\end{tabular} & $\begin{array}{l}\text { Body } \\
\text { Mass } \\
(\mathrm{kg})\end{array}$ & $\begin{array}{c}\text { Femur } \\
\text { Bone } \\
\text { Mineral } \\
\text { Density } \\
\left(\mathrm{mg} / \mathrm{cm}^{3}\right)\end{array}$ & $\begin{array}{c}\text { Femur } \\
\text { Cross- } \\
\text { Sectional } \\
\text { Area } \\
\left(\mathrm{mm}^{2}\right)\end{array}$ & $\begin{array}{c}\text { Femur } \\
\text { Moment of } \\
\text { Inertia } \\
\left(\mathrm{mm}^{4}\right)\end{array}$ & $\begin{array}{c}\text { Max. } \\
\text { Distance } \\
\text { to } \\
\text { Neutral } \\
\text { Axis } \\
\text { (mm) }\end{array}$ \\
\hline L1 & 2 & Female & 61 & 77.6 & 1062 & 405 & 25630 & 19.22 \\
\hline L2 & 1 & Male & 65 & 68.9 & 1004 & 409 & 21620 & 16.42 \\
\hline L3 & 3 & Male & 49 & 106.6 & 1104 & 621 & 41070 & 20.03 \\
\hline L4 & 5 & Male & 62 & 89.1 & N/A* & 661 & 46950 & 19.43 \\
\hline L5 & 6 & Female & 59 & 64.6 & 1132 & 335 & 14200 & 13.17 \\
\hline L6 & 7 & Male & 83 & 66.4 & 1174 & 555 & 38840 & 16.36 \\
\hline L7 & 9 & Female & 71 & 47.9 & 1165 & 291 & 13550 & 12.77 \\
\hline L8 & 11 & Female & 67 & 63.8 & 1120 & 346 & 16890 & 16.36 \\
\hline L9 & 12 & Male & 65 & 84.7 & 1183 & 441 & 28950 & 14.96 \\
\hline L10 & 14 & Female & 73 & 89.1 & 1011 & 357 & 20520 & 16.76 \\
\hline L11 & 20 & Male & 64 & 65.8 & 1150 & 482 & 27580 & 18.95 \\
\hline L12 & 21 & Female & 61 & 54.0 & 1076 & 276 & 13730 & 12.57 \\
\hline L13 & 22 & Male & 62 & 99.3 & 1116 & 456 & 40260 & 17.96 \\
\hline L14 & 23 & Male & 71 & 71.2 & 1239 & 407 & 19940 & 16.16 \\
\hline L15 & 24 & Male & 61 & 107.1 & 968 & 427 & 52200 & 18.35 \\
\hline L16 & 25 & Male & 61 & 116.6 & 1118 & 452 & 26480 & 16.76 \\
\hline $\mathrm{L} 17$ & 26 & Male & 64 & 90.7 & 1087 & 473 & 42110 & 16.76 \\
\hline L18 & 28 & Male & 78 & 104.8 & 1104 & 467 & 26890 & 16.56 \\
\hline L19 & 21 & Female & 61 & 54.0 & 1098 & 249 & 12600 & 12.97 \\
\hline L20 & 22 & Male & 62 & 99.3 & 1104 & 474 & 38090 & 18.35 \\
\hline L21 & 24 & Male & 61 & 107.1 & 998 & 433 & 50940 & 17.04 \\
\hline $\mathrm{L} 22$ & 25 & Male & 61 & 116.6 & 1115 & 451 & 27800 & 16.16 \\
\hline L23 & 27 & Female & 72 & 73.9 & 1032 & 254 & 12930 & 15.96 \\
\hline L24 & 29 & Female & 67 & 63.4 & 1061 & 322 & 19200 & 14.36 \\
\hline $\mathrm{L} 25$ & 29 & Female & 67 & 63.4 & 1057 & 327 & 17370 & 15.16 \\
\hline \multicolumn{2}{|c|}{ Average } & \multirow{2}{*}{$\begin{array}{l}15 \text { Male; } \\
10 \text { Female }\end{array}$} & 65 & 81.8 & 1095 & 415 & 27850 & 16.38 \\
\hline \multicolumn{2}{|c|}{$\begin{array}{l}\text { Standard } \\
\text { Deviation }\end{array}$} & & 7 & 20.9 & 64 & 104 & 12520 & 2.10 \\
\hline
\end{tabular}

* Bone mineral density was not available from the QCT scan for this test. 
Table 3: Cadaver subject information for posterior bending tests.

\begin{tabular}{|c|c|c|c|c|c|c|c|c|}
\hline $\begin{array}{c}\text { Test } \\
\text { Number }\end{array}$ & $\begin{array}{c}\text { Subject } \\
\text { Number }\end{array}$ & Gender & $\begin{array}{c}\text { Age } \\
\text { (years) }\end{array}$ & $\begin{array}{l}\text { Body } \\
\text { Mass } \\
(\mathrm{kg}) \\
\end{array}$ & $\begin{array}{c}\text { Femur } \\
\text { Bone } \\
\text { Mineral } \\
\text { Density } \\
\left(\mathrm{mg} / \mathrm{cm}^{3}\right) \\
\end{array}$ & $\begin{array}{c}\text { Femur } \\
\text { Cross- } \\
\text { Sectional } \\
\text { Area } \\
\left(\mathrm{mm}^{2}\right) \\
\end{array}$ & $\begin{array}{c}\text { Femur } \\
\begin{array}{c}\text { Moment of } \\
\text { Inertia }\end{array} \\
\left(\mathrm{mm}^{4}\right)\end{array}$ & $\begin{array}{c}\text { Max. } \\
\text { Distance } \\
\text { to } \\
\text { Neutral } \\
\text { Axis } \\
(\mathrm{mm}) \\
\end{array}$ \\
\hline P1 & 1 & Male & 65 & 69.9 & 1068 & 389 & 26360 & 14.42 \\
\hline $\mathrm{P} 2$ & 2 & Female & 61 & 77.6 & 1026 & 457 & 39710 & 18.82 \\
\hline P3 & 3 & Male & 49 & 107.0 & 1090 & 551 & 56130 & 16.42 \\
\hline P4 & 4 & Female & 68 & 95.1 & 1058 & 376 & 28700 & 15.22 \\
\hline P5 & 5 & Male & 62 & 89.1 & $\mathrm{~N} / \mathrm{A}^{*}$ & 614 & 65870 & 19.43 \\
\hline P6 & 6 & Female & 59 & 64.6 & 1098 & 305 & 16420 & 12.77 \\
\hline P7 & 7 & Male & 83 & 66.4 & 1180 & 557 & 37480 & 16.16 \\
\hline P8 & 8 & Female & 70 & 57.6 & 1129 & 373 & 23550 & 12.57 \\
\hline P9 & 9 & Female & 71 & 47.9 & 1176 & 316 & 14720 & 12.77 \\
\hline P10 & 10 & Male & 56 & 52.4 & 1109 & 490 & 39010 & 16.82 \\
\hline P11 & 11 & Female & 67 & 63.8 & 1117 & 358 & 23770 & 12.97 \\
\hline P12 & 12 & Male & 65 & 84.7 & 1170 & 431 & 28510 & 15.76 \\
\hline P13 & 8 & Female & 70 & 57.6 & 1181 & 309 & 20890 & 12.17 \\
\hline P14 & 13 & Male & 74 & 59.0 & 1112 & 294 & 21110 & 14.16 \\
\hline P15 & 14 & Female & 71 & 89.1 & 1008 & 318 & 22190 & 13.97 \\
\hline P16 & 15 & Male & 68 & 99.8 & 1069 & 428 & 45080 & 16.16 \\
\hline $\mathrm{P} 17$ & 16 & Male & 69 & 57.6 & 1102 & 535 & 40090 & 16.56 \\
\hline P18 & 17 & Male & 64 & 72.6 & 1081 & 515 & 44420 & 16.16 \\
\hline P19 & 18 & Female & 74 & 61.2 & 1175 & 411 & 23670 & 13.57 \\
\hline P20 & 19 & Female & 73 & 59.0 & 975 & 294 & 15360 & 13.77 \\
\hline \multicolumn{2}{|c|}{ Average } & \multirow{2}{*}{$\begin{array}{l}10 \text { Male; } \\
10 \text { Female }\end{array}$} & 67 & 71.6 & 1101 & 416 & 31650 & 15.03 \\
\hline \multicolumn{2}{|c|}{$\begin{array}{l}\text { Standard } \\
\text { Deviation }\end{array}$} & & 7 & 17.0 & 60 & 100 & 13910 & 2.06 \\
\hline
\end{tabular}

* Bone mineral density was not available from the QCT scan for this test.

\section{Statistical Analysis}

Data were analyzed using regression and survival analysis methods. First, regression analysis was used to relate peak moment to the other variables (gender, age, occupant mass, $\mathrm{BMD}$, cross-sectional area, area moment of inertia, $c, I / c$, leg aspect, and loading direction) and 
to identify subsets of variables that are most useful in predicting femur fracture. The regression analysis evaluated all possible models and all possible combinations of variables. A variable was considered significant if the p-value was 0.05 or less. The best model was selected based on significance of the model, the model parameters, and regression criteria such as the correlation coefficient $\left(\mathrm{R}^{2}\right)$ and Mallow's $\mathrm{C}_{\mathrm{p}}$ statistic $\left(\mathrm{C}_{\mathrm{p}}\right)$. To account for the potential correlation from using the same cadaver, a mixed model regression was used to test significance of the variable or model (Littell et al. 1996). The mixed model included two error or random terms; one due to cadaver and the second due to measurement. Tests of hypotheses use mean square errors that are based on cadaver variation as well as measurement variation.

In order to develop risk functions for different variables and sets of variables, survival analysis methodology was utilized. Parametric survival analysis (Collett 1999) was used to develop the risk functions using a Weibull distribution and to evaluate the effects of covariates on the risk functions. SAS/STAT (SAS 1996) was used to fit and evaluate the models and estimate the risk functions (Cantor 1997). Risk functions have been developed using two methods: utilizing localized geometric descriptors to calculate risk of femur fracture, and utilizing global occupant parameters to predict risk of femur fracture.

In the survival analysis, to adjust for the potential for dependence between observations from the same cadaver, significance of parameters was evaluated using a bootstrap approach. The bootstrap is a resampling method commonly used for estimating variance of parameters in complex settings (Collett 1999). In this analysis, cadavers were resampled from the set and the Weibull model estimated. The resampling was repeated 1000 times to generate 1000 potential models. Significance of variables in the model was evaluated by calculating the number of 
parameter estimates that were more extreme than zero. The proportion of values more extreme than zero was used to estimate the p-value for the significance of a variable in the model.

Geometric values for $I / c$ and cross-sectional area were estimated for male and female populations by utilizing the empirical distribution function for the geometric data from the femur samples used for the experiment. From this distribution, values of $I / c$ and cross-sectional area were estimated for the $5^{\text {th }}, 50^{\text {th }}$, and $95^{\text {th }}$ percentiles of male and female populations. These were used in conjunction with the Weibull-based risk functions to generate risk curves based on these geometric properties across population subsets. 


\section{RESULTS}

\section{Experimental Data}

Data from the in situ strain gage indicate that the average strain at failure is $1.3 \pm 0.3$ percent for lateral bending and $1.2 \pm 0.3$ percent for posterior loading (Table 4 and Table 5). The lateral bending tests were performed at an average strain rate of $5.0 \pm 1.2 \mathrm{sec}^{-1}$, while the posterior bending tests were performed at an average strain rate of $4.7 \pm 1.1 \mathrm{sec}^{-1}$. In all 45 tests, the fracture occurred at the site of the strain gage. Fracture patterns were similar for both directions and included 16 oblique, 7 comminuted oblique, 2 wedge, 9 comminuted wedge, 5 transverse, 2 comminuted transverse, and 4 indeterminate comminuted.

Experimental data show large differences between peak impactor load and the peak reaction load, which is the sum of the two support loads. The differences in peak bending moments as calculated from the inertially compensated impactor load versus the support reaction loads is observable (Figure 4 and Figure 5). The peak reaction moment occurs just after the peak impactor moment, as the load is transferred from the impactor through the femur to the reaction supports. The peak strain occurs at approximately the same time that the femur fractures, as the strain gage is located contralaterally to the impacting site of the blade. For the statistical analysis of the data, the reaction moment is chosen over the impactor moment. Additional background for this choice is presented in the discussion section. All subsequent data and analysis is presented using the reaction loads.

Stress-strain plots are utilized to determine the elastic modulus of the bone (Figure 6). The average modulus is found to be $17.77 \pm 5.29 \mathrm{GPa}$ for lateral tests and $15.19 \pm 2.58 \mathrm{GPa}$ for posterior tests (Table 4 and Table 5). 
Table 4: Filtered sensor data for the lateral bending tests.

\begin{tabular}{|c|c|c|c|c|c|c|c|}
\hline $\begin{array}{c}\text { Test } \\
\text { Number }\end{array}$ & $\begin{array}{c}\text { Peak Impactor } \\
\text { Load } \\
(\mathrm{N}) \\
\end{array}$ & $\begin{array}{c}\text { Peak } \\
\text { Reaction } \\
\text { Load } \\
(\mathrm{N})\end{array}$ & $\begin{array}{c}\text { Span } \\
\text { Length } \\
(\mathrm{m})\end{array}$ & $\begin{array}{c}\text { Peak } \\
\text { Reaction } \\
\text { Moment } \\
(\mathrm{Nm})\end{array}$ & $\begin{array}{c}\text { Peak } \\
\text { Elastic } \\
\text { Stress } \\
(\mathrm{MPa})\end{array}$ & $\begin{array}{c}\text { Elastic } \\
\text { Modulus } \\
(\mathrm{GPa})\end{array}$ & $\begin{array}{c}\text { Peak Strain } \\
(\%) \\
\end{array}$ \\
\hline L1 & 4590 & 3900 & 0.344 & 335 & 251.3 & 26.11 & 1.204 \\
\hline L2 & 4110 & 3570 & 0.356 & 318 & 241.2 & 22.27 & 1.283 \\
\hline L3 & 4950 & 3920 & 0.452 & 443 & 216.2 & 15.82 & 1.203 \\
\hline L4 & 6960 & 6220 & 0.348 & 541 & 223.9 & 15.79 & 1.345 \\
\hline L5 & 4310 & 3620 & 0.300 & 272 & 252.1 & 15.54 & 1.176 \\
\hline L6 & 5840 & 4960 & 0.345 & 428 & 180.3 & 25.59 & 1.093 \\
\hline L7 & 4130 & 3720 & 0.277 & 258 & 242.9 & 24.83 & 0.932 \\
\hline L8 & 4320 & 3760 & 0.298 & 280 & 271.2 & $\mathrm{~N} / \mathrm{A}^{*}$ & N/A* \\
\hline L9 & 5890 & 5100 & 0.340 & 434 & 224.3 & 20.02 & 1.059 \\
\hline L10 & 4000 & 3260 & 0.345 & 281 & 229.8 & 12.46 & 1.428 \\
\hline L11 & 5240 & 4930 & 0.322 & 396 & 272.5 & 21.28 & 1.418 \\
\hline L12 & 3830 & 3250 & 0.307 & 249 & 228.1 & 13.40 & 1.720 \\
\hline L13 & 5680 & 4920 & 0.360 & 443 & 197.4 & 17.03 & 0.832 \\
\hline L14 & 4270 & 3740 & 0.345 & 322 & 261.1 & 33.07 & 0.960 \\
\hline L15 & 4430 & 3660 & 0.305 & 279 & 98.0 & 16.40 & 0.517 \\
\hline L16 & 5030 & 4850 & 0.338 & 410 & 259.4 & 13.91 & 1.383 \\
\hline L17 & 5810 & 5510 & 0.360 & 496 & 197.4 & 13.85 & 1.434 \\
\hline L18 & 4890 & 4140 & 0.337 & 349 & 214.7 & 15.58 & 1.378 \\
\hline L19 & 3420 & 3160 & 0.293 & 231 & 238.1 & 17.84 & 1.094 \\
\hline L20 & 4910 & 4240 & 0.390 & 414 & 199.3 & 14.16 & 1.787 \\
\hline L21 & 4630 & 3920 & 0.376 & 368 & 123.2 & 14.26 & 0.877 \\
\hline L22 & 4910 & 4360 & 0.327 & 357 & 207.4 & 12.05 & 1.349 \\
\hline L23 & 4050 & 3560 & 0.300 & 267 & 329.2 & 17.90 & 1.425 \\
\hline L24 & 4950 & 4300 & 0.310 & 333 & 249.4 & 12.71 & 1.522 \\
\hline L25 & 4500 & 3840 & 0.308 & 296 & 258.3 & 14.54 & 1.705 \\
\hline Average & 4780 & 4180 & 0.335 & 352 & 226.7 & 17.77 & 1.255 \\
\hline $\begin{array}{l}\text { Standard } \\
\text { Deviation }\end{array}$ & 792 & 764 & 0.037 & 83 & 46.9 & 5.29 & 0.302 \\
\hline
\end{tabular}

* Sensor failure prior to fracture event 
Table 5: Filtered sensor data for the posterior bending tests.

\begin{tabular}{|c|c|c|c|c|c|c|c|}
\hline $\begin{array}{c}\text { Test } \\
\text { Number }\end{array}$ & $\begin{array}{c}\text { Peak Impactor } \\
\text { Load } \\
(\mathrm{N}) \\
\end{array}$ & $\begin{array}{c}\text { Peak } \\
\text { Reaction } \\
\text { Load } \\
(\mathrm{N})\end{array}$ & $\begin{array}{c}\text { Span } \\
\text { Length } \\
(\mathrm{m}) \\
\end{array}$ & $\begin{array}{c}\text { Peak } \\
\text { Reaction } \\
\text { Moment } \\
(\mathrm{Nm})\end{array}$ & $\begin{array}{c}\text { Peak } \\
\text { Elastic } \\
\text { Stress } \\
(\mathrm{MPa}) \\
\end{array}$ & $\begin{array}{c}\text { Elastic } \\
\text { Modulus } \\
(\mathrm{GPa}) \\
\end{array}$ & $\begin{array}{c}\text { Peak Strain } \\
(\%) \\
\end{array}$ \\
\hline $\mathrm{P} 1$ & 3570 & 3060 & 0.390 & 298 & 163.0 & 14.82 & 1.580 \\
\hline $\mathrm{P} 2$ & 4410 & 3800 & 0.393 & 373 & 176.8 & 12.59 & 1.160 \\
\hline P3 & 4690 & 3910 & 0.457 & 447 & 130.8 & 15.25 & 0.981 \\
\hline $\mathrm{P} 4$ & 4090 & 3530 & 0.379 & 334 & 177.1 & 14.21 & 1.250 \\
\hline P5 & 6220 & 5400 & 0.418 & 564 & 166.4 & 18.37 & 0.926 \\
\hline P6 & 3000 & 2680 & 0.376 & 252 & 196.0 & 11.13 & 1.600 \\
\hline P7 & 5310 & 4700 & 0.365 & 429 & 185.0 & 17.13 & 1.060 \\
\hline P8 & 3880 & 3230 & 0.382 & 308 & 164.4 & 14.99 & 1.330 \\
\hline P9 & 3090 & 2770 & 0.320 & 222 & 192.5 & 16.36 & 1.050 \\
\hline P10 & 5420 & 4810 & 0.332 & 399 & 172.0 & 11.71 & 0.782 \\
\hline P11 & 4580 & 4030 & 0.332 & 334 & 182.2 & 13.78 & 1.410 \\
\hline P12 & 4680 & 4100 & 0.364 & 373 & 206.2 & 18.45 & 1.060 \\
\hline P13 & 3640 & 3190 & 0.340 & 271 & 157.9 & 20.00 & 1.750 \\
\hline P14 & 2530 & 2340 & 0.378 & 221 & 148.3 & 16.04 & 0.707 \\
\hline P15 & 3430 & 2927 & 0.365 & 267 & 168.0 & 11.49 & 1.603 \\
\hline P16 & 5050 & 4520 & 0.365 & 412 & 147.7 & 14.21 & 1.010 \\
\hline P17 & 5490 & 4920 & 0.356 & 438 & 180.9 & 19.60 & 0.805 \\
\hline P18 & 5510 & 5030 & 0.363 & 456 & 165.9 & 13.51 & 1.620 \\
\hline P19 & 4770 & 4240 & 0.350 & 371 & 212.6 & 14.25 & 1.220 \\
\hline P20 & 2770 & 2430 & 0.302 & 184 & 164.9 & 15.95 & 0.902 \\
\hline Average & 4310 & 3780 & 0.366 & 348 & 172.9 & 15.19 & 1.190 \\
\hline $\begin{array}{l}\text { Standard } \\
\text { Deviation }\end{array}$ & 1040 & 930 & 0.034 & 96 & 19.9 & 2.58 & 0.316 \\
\hline
\end{tabular}




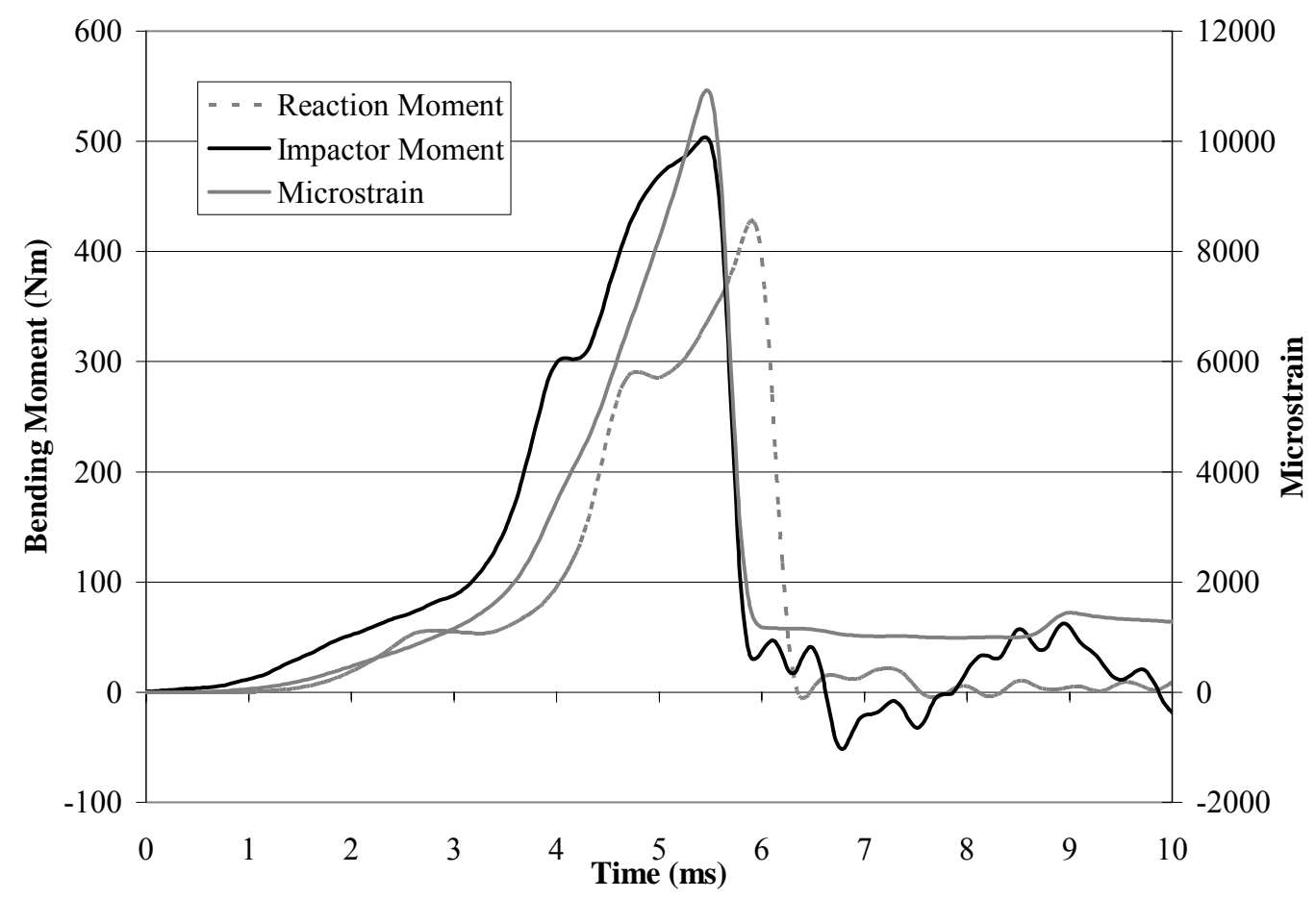

Figure 4: Calculated bending moments from reaction and impactor load cells (left axis) and microstrain from strain gage on test specimen (right axis) from test number L6.

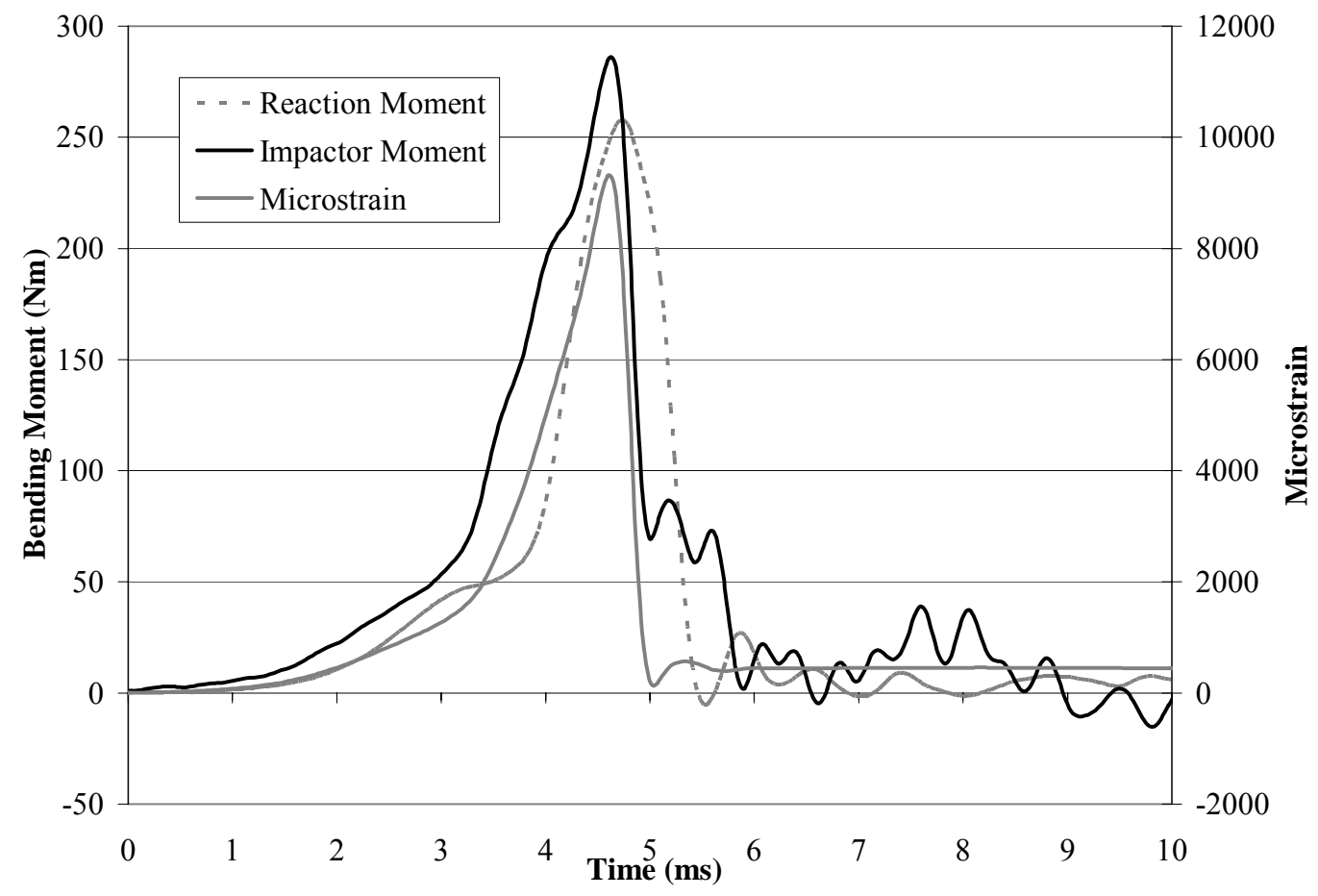

Figure 5: Calculated bending moments from reaction and impactor load cells (left axis) and microstrain from strain gage on test specimen (right axis) from test number L7. 


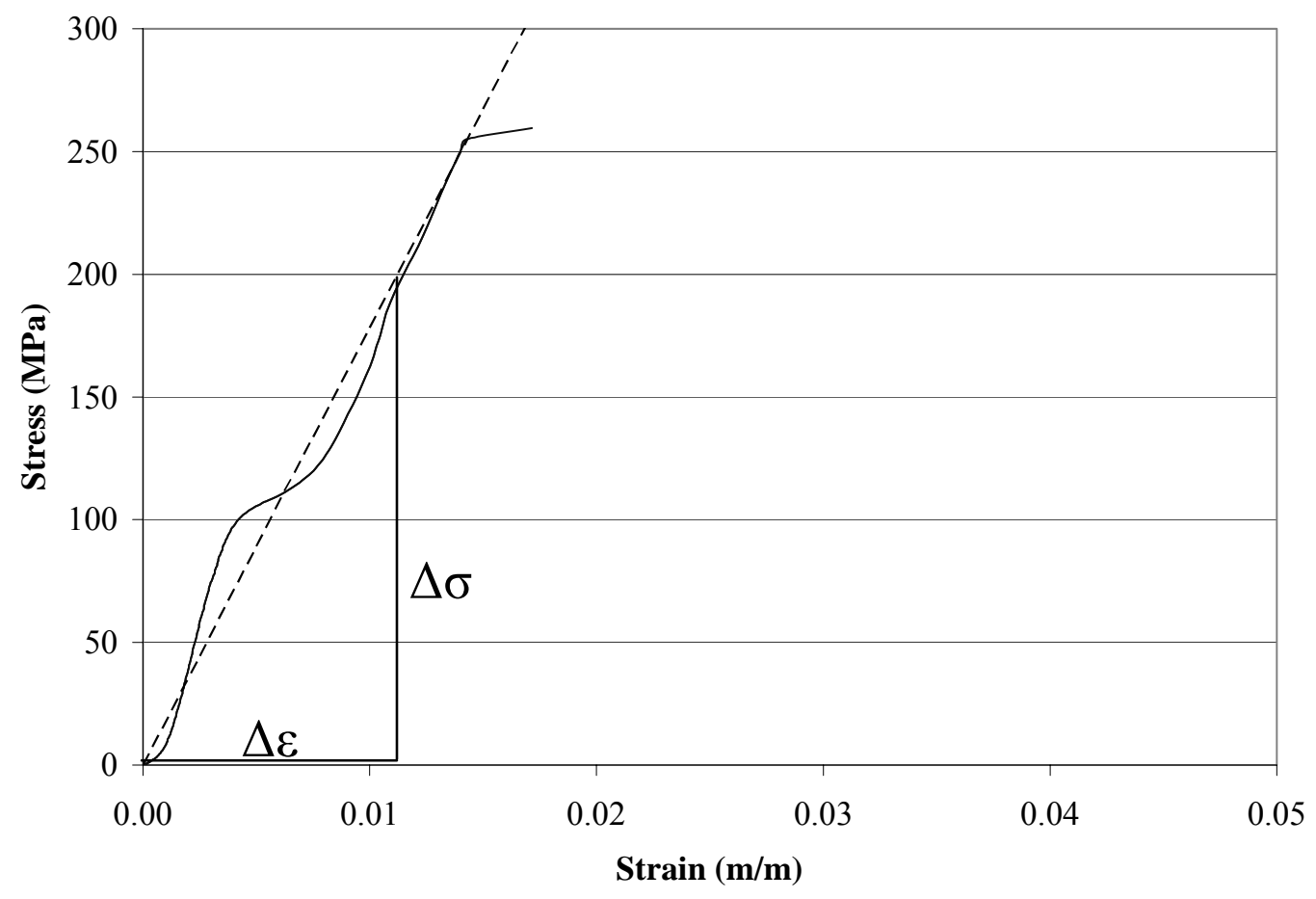

Figure 6: Stress-strain curve used for determination of elastic modulus of femur.

\section{Statistical Analysis}

The analysis for single variable regression models with peak moment as the dependent variable show that the most important variables are area, mass, inertia, $c, I / c$, and gender (Table 6). The cross-sectional area is well correlated to peak bending moment $\left(\mathrm{R}^{2}=0.77\right)$ and is a significant $(\mathrm{p}=0.0001)$ predictor of fracture (Figure 7). Age is not well correlated with peak bending moment in this study $\left(\mathrm{R}^{2}=0.05\right)$ and though it influences peak bending moment, it is not found to be significant $(\mathrm{p}=0.1423$ ) (Figure 8 ). Mass only modestly correlates with peak bending moment $\left(\mathrm{R}^{2}=0.22\right)$ but has a significant effect on predicting fracture $(\mathrm{p}=0.0258)$ (Figure 9). Bone mineral density of the femur does not correlate well with peak bending moment $\left(\mathrm{R}^{2}=0.05\right)$ and is not significant $(\mathrm{p}=0.3097)$ (Figure 10). Alternative plots of bending moment normalized to cross-sectional area versus age, versus mass, and versus bone mineral density are presented in Appendix A (Figure A1, Figure A2, and Figure A3). The five variables 
of area, mass, inertia, $I / c$, and gender are correlated with each other (Table 7). Because of their significance and the fact that they correlate with peak bending moment, the model selection procedures result in two models: one that contains only the variable area, and one that contains only the variable $I / c$.

Loading direction is not correlated with peak bending moment $\left(\mathrm{R}^{2}=0.01\right)$ and is not found to be significant $(\mathrm{p}=0.7856)$ (Figure 11). It is also seen that the leg tested does not have an effect on peak bending moment $\left(\mathrm{R}^{2}=0.01\right)$ and is not significant $(\mathrm{p}=0.5652)($ Figure 12).

Table 6: Results from the regression analysis on factors related to peak reaction moment. Significance is based on the mixed model tests.

\begin{tabular}{|l|r|r|c|}
\hline \multicolumn{1}{|c|}{ Variable } & $\mathrm{R}^{2}$ & $\mathrm{t}$-test & $\mathrm{p}$-value \\
\hline Area & 0.77 & 12.59 & 0.0001 \\
\hline Age & 0.05 & -1.55 & 0.1423 \\
\hline Mass & 0.22 & 2.47 & 0.0258 \\
\hline Density & 0.05 & 1.05 & 0.3097 \\
\hline Inertia & 0.57 & 7.35 & 0.0001 \\
\hline Direction & 0.01 & 0.28 & 0.7856 \\
\hline$c$ & 0.45 & 5.91 & 0.0001 \\
\hline Gender & 0.44 & -4.38 & 0.0005 \\
\hline$I / c$ & 0.56 & 7.47 & 0.0001 \\
\hline Leg & 0.01 & -0.59 & 0.5652 \\
\hline
\end{tabular}

Table 7: Pearson correlation coefficients for peak moment and other variables.

\begin{tabular}{|c|c|c|c|c|c|c|c|c|c|c|c|}
\hline & Moment & $c$ & Age & Mass & Density & Inertia & Area & $I / c$ & Gender & Leg & Direction \\
\hline Moment & 1.000 & & & & & & & & & & \\
\hline$c$ & 0.604 & 1.000 & & & & & & & & & \\
\hline Age & -0.213 & -0.270 & 1.000 & & & & & & & & \\
\hline Mass & 0.469 & 0.591 & -0.338 & 1.000 & & & & & & & \\
\hline Density & 0.226 & -0.222 & 0.214 & -0.281 & 1.000 & & & & & & \\
\hline Inertia & 0.757 & 0.632 & -0.310 & 0.579 & -0.157 & 1.000 & & & & & \\
\hline Area & 0.880 & 0.700 & -0.191 & 0.473 & 0.179 & 0.803 & 1.000 & & & & \\
\hline$I / c$ & 0.714 & -0.084 & -0.237 & 0.488 & -0.091 & 0.964 & 0.727 & 1.000 & & & \\
\hline Gender & -0.663 & -0.557 & 0.136 & -0.493 & -0.151 & -0.677 & -0.739 & -0.620 & 1.000 & & \\
\hline Leg & -0.036 & -0.091 & -0.140 & 0.018 & -0.005 & 0.046 & -0.050 & 0.074 & 0.015 & 1.000 & \\
\hline Direction & 0.051 & -0.130 & -0.137 & 0.272 & -0.051 & -0.118 & -0.005 & -0.278 & -0.109 & -0.151 & 1.000 \\
\hline
\end{tabular}




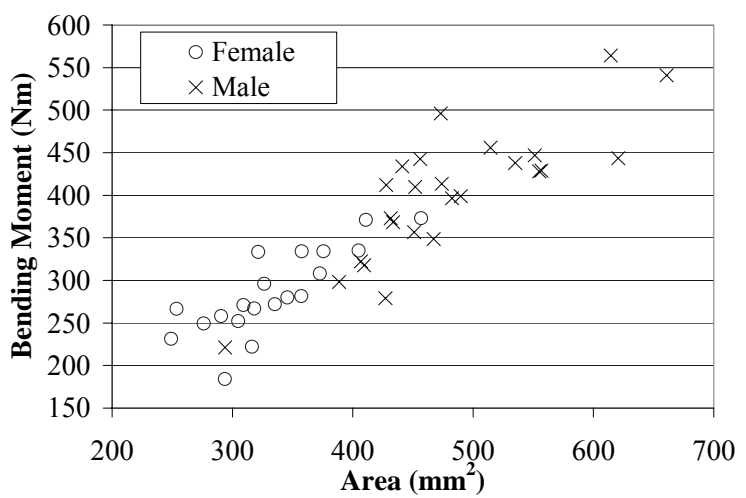

Figure 7: Bending moment vs. cross-sectional area.

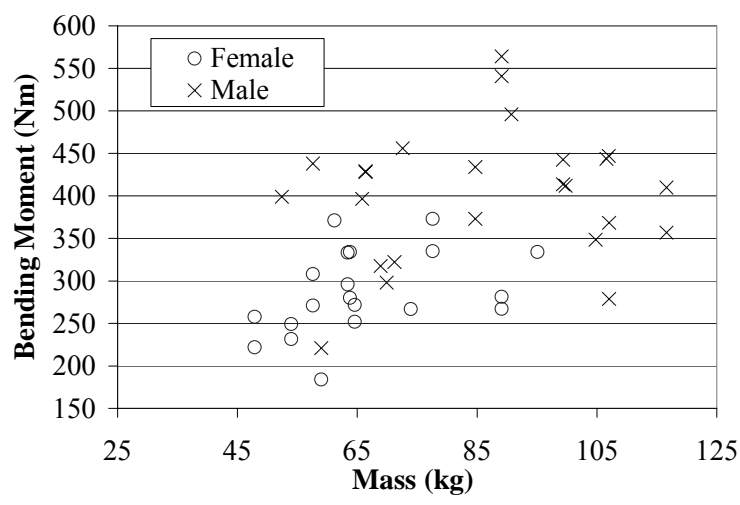

Figure 9: Bending moment vs. mass.

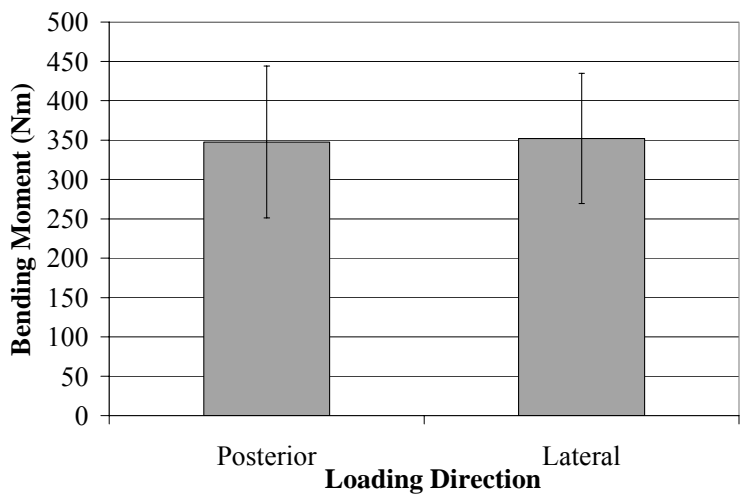

Figure 11: Bending moment vs. loading direction.

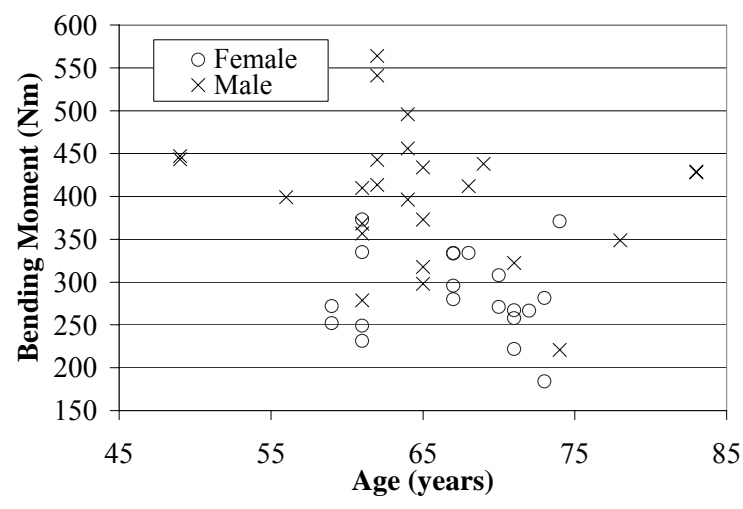

Figure 8: Bending moment vs. age.

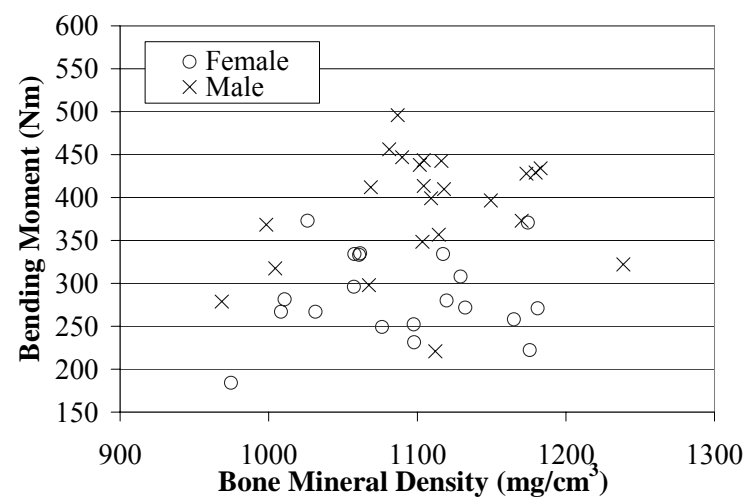

Figure 10: Bending moment vs. bone mineral density.

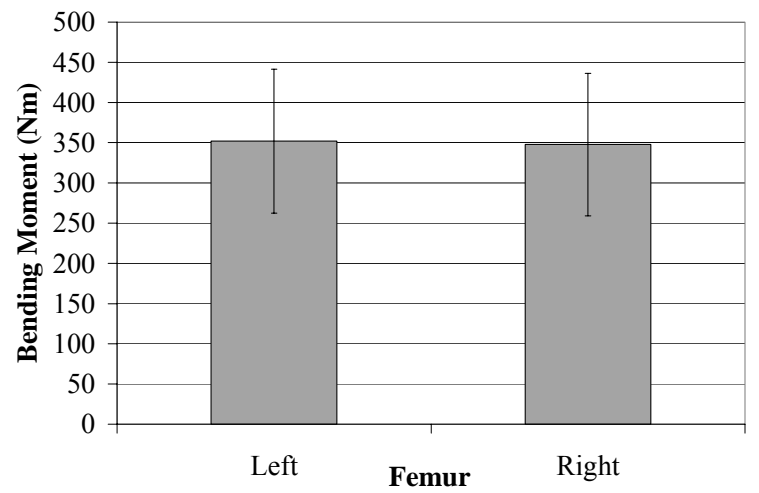

Figure 12: Bending moment vs. leg. 
Additional plots are presented to correlate geometric factors to experimental variables. Bending moment is found to be correlated with $I / c\left(\mathrm{R}^{2}=0.56\right)$, but is a significant predictor of fracture $(\mathrm{p}=0.0001)$ (Figure 13). Bending moment normalized to $I / \mathrm{c}$ is not correlated with the age of the donor $\left(\mathrm{R}^{2}=0.01\right)$ (Figure 14$)$. The geometric descriptor $(I / c)$ modestly correlates with mass $\left(\mathrm{R}^{2}=0.24\right)$ (Figure 15$)$. The geometric descriptor $(I / c)$ is not correlated with bone mineral density $\left(\mathrm{R}^{2}=0.01\right)$ (Figure 16$)$. Substituting cross-sectional area for $I / c$ it is found that crosssectional area modestly correlates with mass $\left(\mathrm{R}^{2}=0.22\right)$ (Figure 17). The correlation between cross-sectional area and bone mineral density shows no correlation $\left(\mathrm{R}^{2}=0.03\right)$ (Figure 18). Additional plots of bending moment normalized to $I / c$ versus mass and versus bone mineral density are included in Appendix A (Figure A4 and Figure A5).

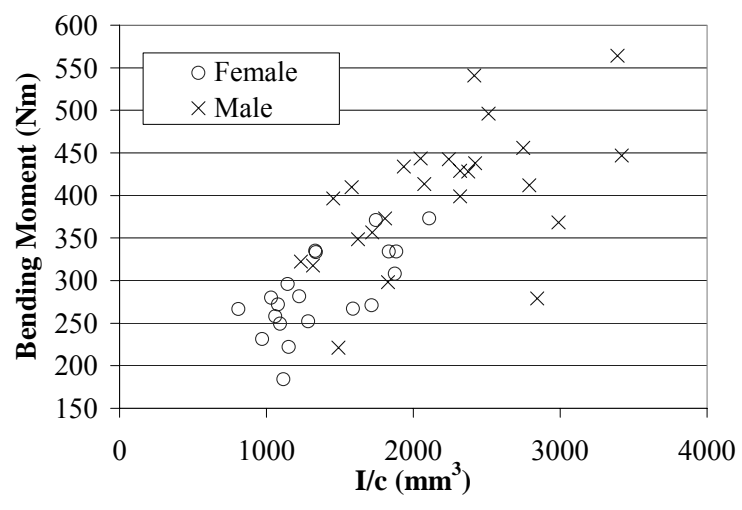

Figure 13: Bending moment vs. $I / c$.

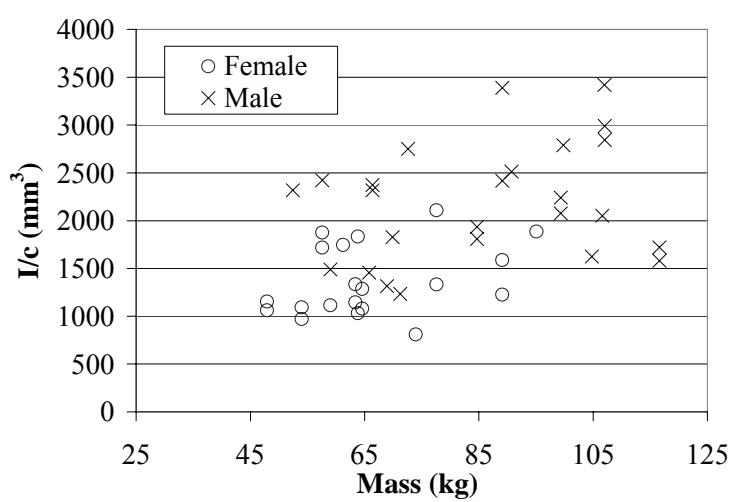

Figure 15: $I / c$ vs. mass.

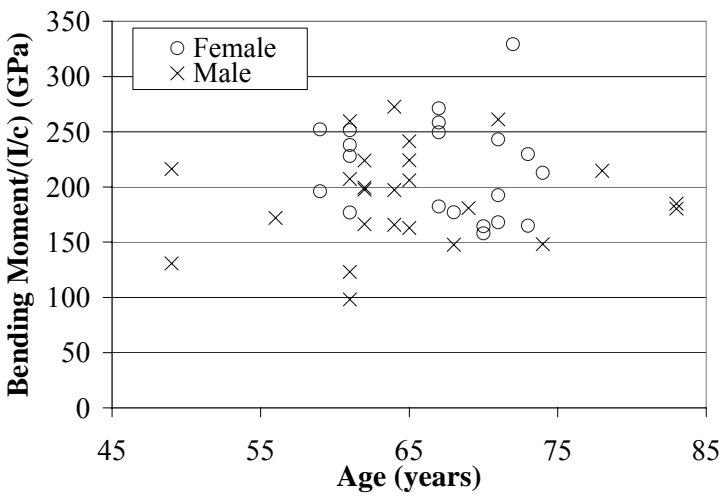

Figure 14: Bending moment normalized to $I / c$ vs. age.

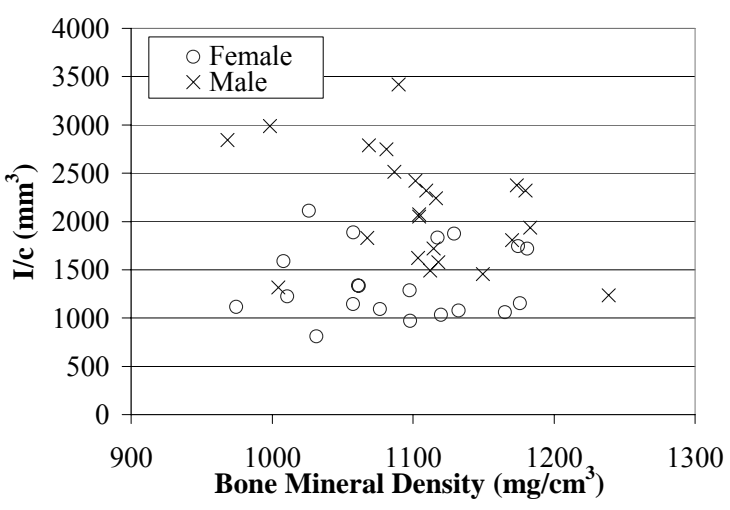

Figure 16: $I / c$ vs. bone mineral density. 


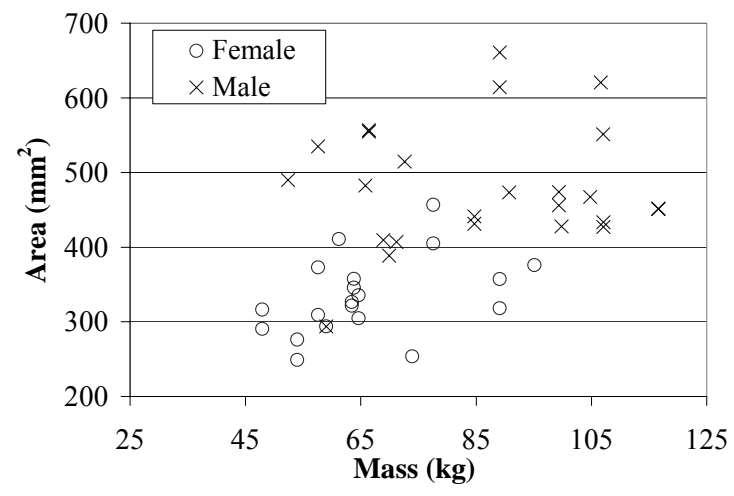

Figure 17: Cross-sectional area vs. mass.

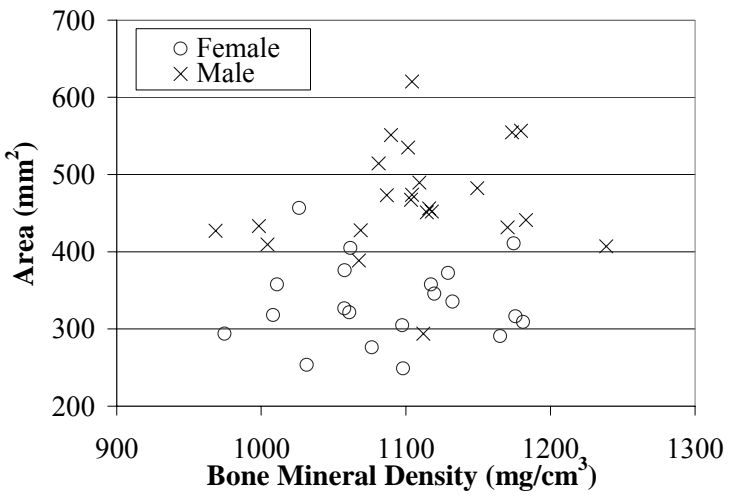

Figure 18: Cross-sectional area vs. bone mineral density.

Cross-sectional area is estimated for the $5^{\text {th }}, 50^{\text {th }}$, and $95^{\text {th }}$ percentile males and females based on an empirical distribution analysis of test specimen geometric data (Table 8). I/c percentiles are estimated using the same methodology.

Table 8: Percentile estimates of cross-sectional area and $I / c$ based on specimen data.

\begin{tabular}{|c|c|c|c|}
\cline { 2 - 4 } \multicolumn{1}{c|}{ Male } & Percentile & Area $\left(\mathrm{mm}^{2}\right)$ & $I / c\left(\mathrm{~mm}^{3}\right)$ \\
\cline { 2 - 4 } & $5^{\text {th }}$ & 388.65 & 1316.46 \\
\cline { 2 - 4 } & $50^{\text {th }}$ & 467.26 & 2242.11 \\
\hline \multirow{3}{*}{ Female } & $95^{\text {th }}$ & 620.59 & 3390.17 \\
\cline { 2 - 4 } & $5^{\text {th }}$ & 251.23 & 888.38 \\
\cline { 2 - 4 } & $50^{\text {th }}$ & 324.03 & 1254.84 \\
\hline & $95^{\text {th }}$ & 433.54 & 1995.72 \\
\hline
\end{tabular}

Using parametric survival analysis, the general formula for the risk function based on the Weibull distribution using a linear predictor is given in Equation 8.

Risk of Femur Fracture (moment, linear predictor $)=1-e^{-e^{\left[\frac{1}{\sigma} \ln (\text { moment })-\frac{\text { linear predictor }}{\sigma}\right]}}$

In this equation, the $\sigma$ is the scale parameter and $1 / \sigma$ is the shape parameter from the Weibull distribution. For example, Equation 9 presents the model that uses area as a linear predictor to adjust risk, where $\beta_{0}$ is the intercept and $\beta_{1}$ is the slope. 
Risk of Femur Fracture (moment, area $)=1-e^{\left.-e^{\left[\frac{1}{\sigma} \ln (\text { moment })-\frac{\beta_{0}+\beta_{1} * \text { area }}{\sigma}\right]}\right]}$

Parameter estimates and the shape or scale parameters are presented for area, $I / c$, gender, mass, and age (Table 9). Based on the bootstrap analysis, area, I/c, gender, and mass are statistically significant with p-values of $0.0001,0.0001,0.0001$, and 0.0012 respectively, and it is shown that age is nearly significant $(\mathrm{p}=0.0579)$. Single variable risk functions are then obtained by substituting the estimated parameters into Equation 8. For example, the estimated model using area has a scale parameter equal to 0.1067 , or $1 / 9.3704$. In terms of the estimated parameters, this substitution gives Equation 10.

Risk of Femur Fracture (moment, area $)=1-e^{-e^{[9.3704 * \ln (\text { moment })-(46.3140+0.0216 * \text { area })]}}$

Table 9: Model parameters, test statistics and p-values for significance of models containing single variables; the test of significance is based on the bootstrap analysis.

\begin{tabular}{|l|c|c|c|c|c|}
\hline \multicolumn{1}{|c|}{ Variable } & Area & $I / c$ & Gender & Mass & Age \\
\hline Intercept $\left(\beta_{0}\right)$ & 4.9417 & 5.3437 & 6.0731 & 5.4951 & 6.3644 \\
\hline Slope $\left(\beta_{1}\right)$ & 0.0023 & 0.0003 & -0.3525 & 0.0057 & -0.0063 \\
\hline Scale $(\sigma)$ & 0.1067 & 0.1396 & 0.1631 & 0.2113 & 0.2248 \\
\hline Shape $(1 / \sigma)$ & 9.3704 & 7.1613 & 6.1320 & 4.7333 & 4.4483 \\
\hline $\begin{array}{l}\text { Bootstrap } \\
\text { p-value }\end{array}$ & 0.0001 & 0.0001 & 0.0001 & 0.0012 & 0.0579 \\
\hline
\end{tabular}

Utilizing the injury risk function for the variable area, developed in Equation 10, injury risk curves are presented for the $5^{\text {th }}, 50^{\text {th }}$, and $95^{\text {th }}$ percentile female, as well as the $5^{\text {th }}, 50^{\text {th }}$, and $95^{\text {th }}$ percentile male (Figure 19). Cross-sectional area of the femur is estimated for each percentile occupant by applying the empirical distribution function to the specimen data (Table 8). The injury risk function predicts a 50 percent risk of femur fracture of $240 \mathrm{Nm}, 395 \mathrm{Nm}$, and $562 \mathrm{Nm}$ for the $5^{\text {th }}$ percentile female, $50^{\text {th }}$ percentile male, and $95^{\text {th }}$ percentile male respectively. 


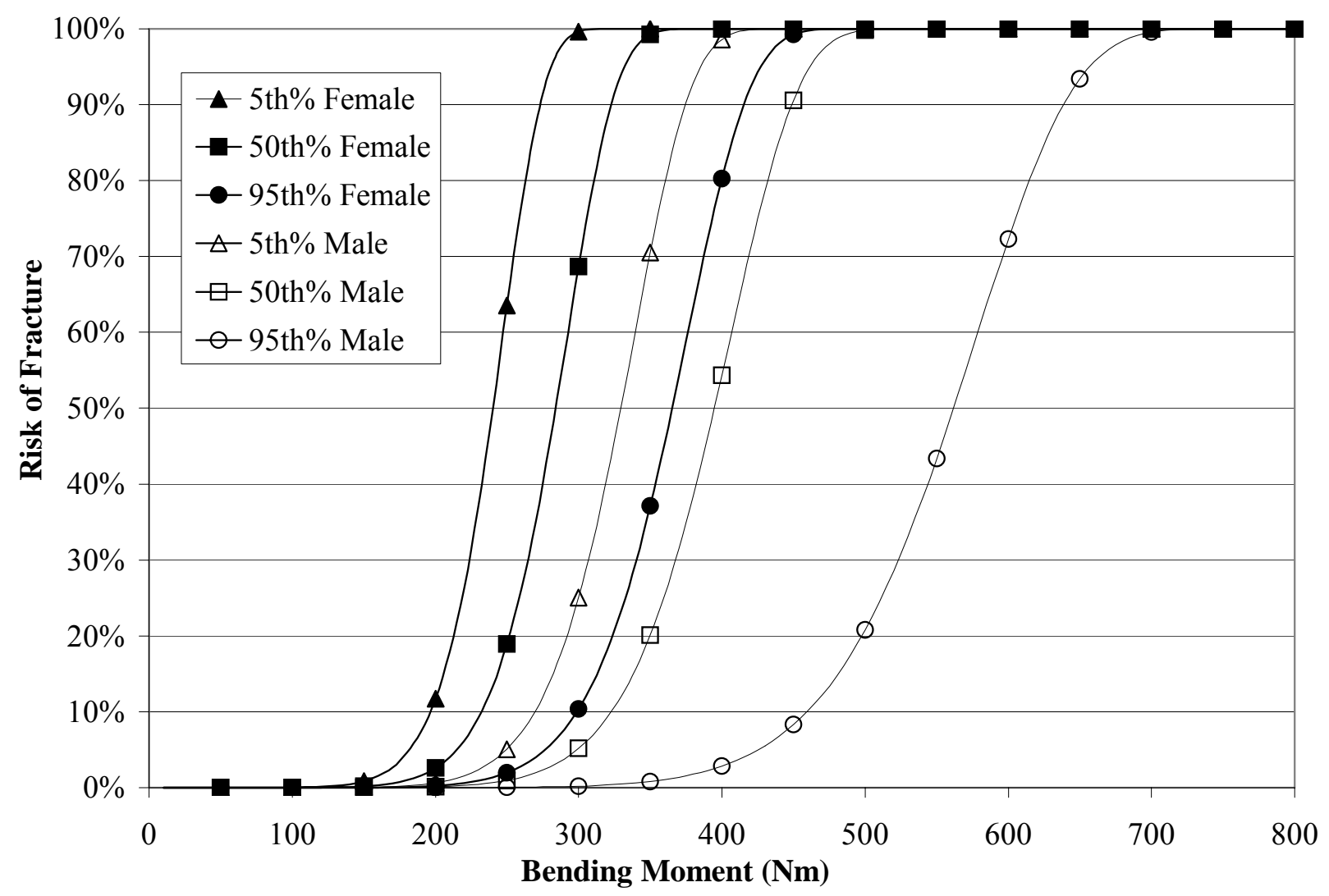

Figure 19: Femur fracture risk curves based on moment and midshaft femur cross-sectional area, geometric variable area is estimated by empirical distribution of specimen data.

Substituting the variable $I / c$ for area yields an alternate risk function (Equation 11). In this equation, the variable moment is the bending moment at the mid-shaft of the femur in Newton-meters, the variable $I / c$ is the geometric property of area moment of inertia divided by the maximum distance to the neutral axis, expressed in $\mathrm{mm}^{3}$.

Risk of Femur Fracture (moment, $I / c)=1-e^{-e^{[7.1613 * \ln (\text { moment })-(38.2787+0.0021 * I / c)]}}$

The risk function for the variable $I / c$, shown in Equation 11, yields a 50 percent risk of femur fracture of $260 \mathrm{Nm}, 390 \mathrm{Nm}$, and $551 \mathrm{Nm}$ for the $5^{\text {th }}$ percentile female, $50^{\text {th }}$ percentile male, and $95^{\text {th }}$ percentile male respectively. Risk curves for the function developed in Equation 
11 are presented for the $5^{\text {th }}, 50^{\text {th }}$, and $95^{\text {th }}$ percentile female, as well as the $5^{\text {th }}, 50^{\text {th }}$, and $95^{\text {th }}$ percentile male in Appendix B (Figure B1). The geometric variable $I / c$ is estimated for each of the six subjects by applying the empirical distribution function to the specimen data (Table 8).

A model using the three variables moment, gender, and mass was generated to predict the risk of femur fracture (Equation 12). In this equation, the variable moment is the bending moment at the mid-shaft of the femur in Newton-meters, the gender variable is a binary identifier where ' 0 ' signifies a male occupant and ' 1 ' represents a female occupant, and the variable mass is equivalent to the weight of the occupant in kilograms.

Risk of Femur Fracture (moment, gender, mass $)=$
\[ 1-e^{-e^{[6.2356 * \ln (\text { moment })-36.6845+1.9657 * \text { gender }-0.0137 * \text { mass }]}} \]

Utilizing the injury risk function developed in Equation 12, a 50 percent risk of femur fracture for the $5^{\text {th }}$ percentile female, $50^{\text {th }}$ percentile male, and $95^{\text {th }}$ percentile male is found to be $274 \mathrm{Nm}, 402 \mathrm{Nm}$, and $420 \mathrm{Nm}$ respectively. Risk curves for the function developed in Equation 12 are presented for the $5^{\text {th }}, 50^{\text {th }}$, and $95^{\text {th }}$ percentile female, as well as the $5^{\text {th }}, 50^{\text {th }}$, and $95^{\text {th }}$ percentile male in Appendix B (Figure B2). Masses used for the $5^{\text {th }}$ percentile female, $50^{\text {th }}$ percentile male and $95^{\text {th }}$ percentile male are $48 \mathrm{~kg}, 78 \mathrm{~kg}$, and $98 \mathrm{~kg}$ respectively (NASA 1978). These masses also correspond to the design parameters of the $5^{\text {th }}$ percentile female, $50^{\text {th }}$ percentile male and $95^{\text {th }}$ percentile male ATDs (SAE 1989). 


\section{DISCUSSION}

\section{Bending Moment Calculations}

The peak impactor loads always measure higher than the peak reaction loads. This is because as the impactor blade contacts the femur, it begins to accelerate the femur and tissue in the impact direction, as well as initiating rotational acceleration of the femur ends. This is explained by D'Alembert's principle with the presence of the inertial term $(m a)$ in Equation 1 and the inertial terms $\left(m_{L} a_{L}\right.$ and $\left.I_{L} \alpha_{L}\right)$ in Equation 2. Although the equations are not solved directly for the inertial terms, the impactor load includes the effect of the inertial response plus the sum of the reaction loads $\left(F_{L R}+F_{R R}\right)$. The reaction load cells allow a conservative calculation of the bending moment of the femur by isolating the inertial effects and larger measured impactor force from the elastic and stiffness effects of the femur (Equation 4 and Equation 5).

In order to properly determine the stiffness of the femur by using the impactor load, the effective mass and acceleration profile of the femur would have to be measured, and the calculated inertial term $(m a)$ subtracted from the impactor load. To demonstrate the effect of this inertial term and show the relationship between the impactor and reaction loads, the inertial term has been estimated by approximating the effective mass and acceleration profile of the test specimen. The effective mass was taken to be one-half that of the total mass of the femur, roller supports and potting cups. The acceleration profile of the impactor while it was in contact with the femur was used to estimate the acceleration of the test specimen.

It is shown that an estimate of the inertial term can be performed and added to the reaction loads (Figure 20). Using these assumptions, the discrepancy between the two measured loads is much reduced. However, the measured impactor load is still approximately $400 \mathrm{~N}$ larger 
than what is calculated with the estimated inertial effects. This is likely because the effect of rotational motion during the event has been assumed negligible in addition to estimation errors for the effective mass and its resultant acceleration pulse.

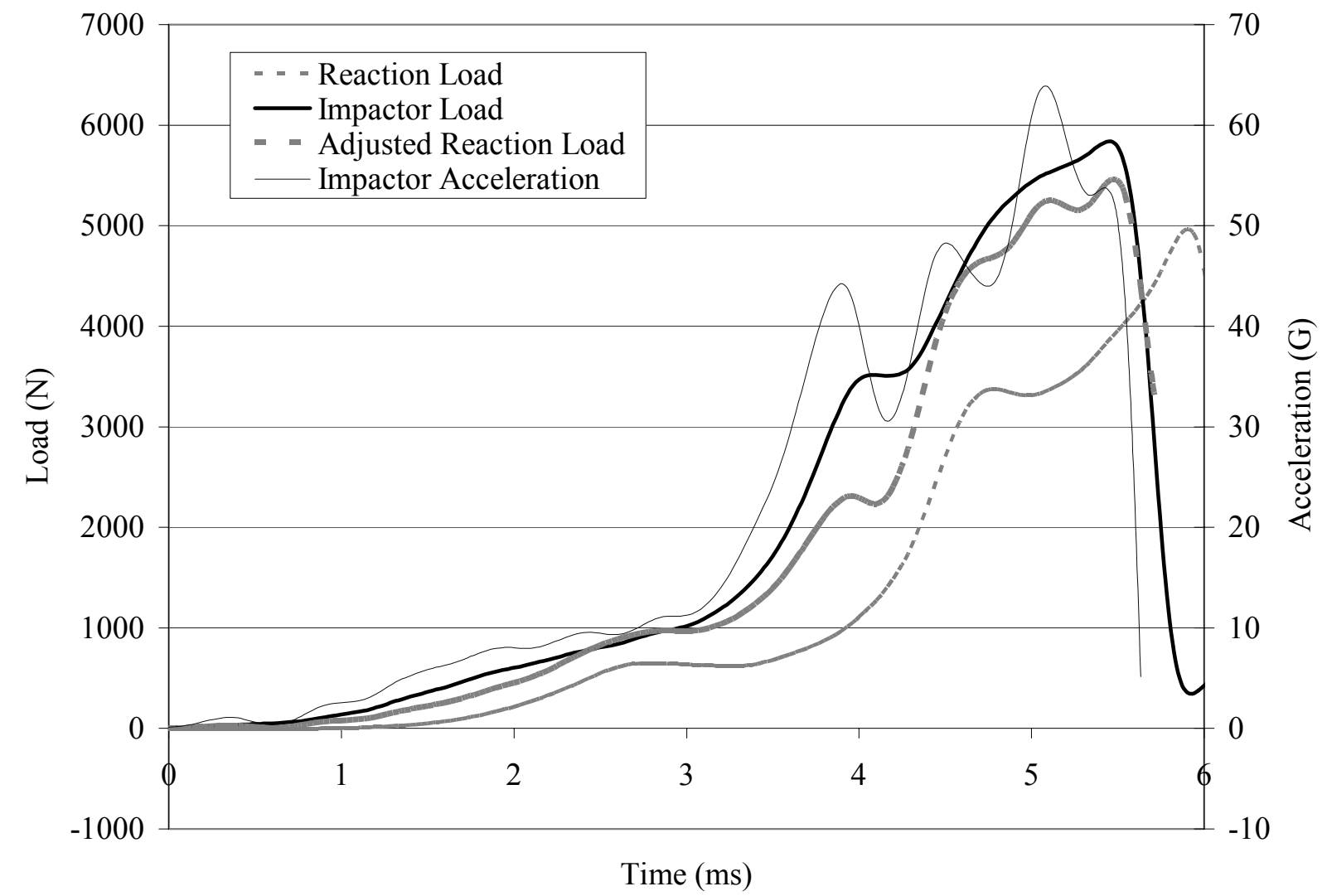

Figure 20: Example of inertial effects present in measured impactor load from test number L6.

Since there is no way to measure the effective mass of the femur, the only way it could exactly be specified would be from using a computational model; however, this is outside the scope of this paper. Since proper characterization of the stiffness properties of the femur is necessary to characterize the fracture criteria, the reaction loads, which have been shown to be free of inertial effects, are used to generate the appropriate injury risk functions.

Another analogy that can be used to explain the difference between the impactor and reaction loads is that of a spring-mass-damper system, which does not include rotational effects 
(Figure 21). In the system shown, the impactor strikes a mass, representing the femur mass, which is supported by a parallel arrangement of a spring and damper, representing the material strength of the femur. The spring and the damper respond to the impact force, but because the impact results in the mass accelerating downward, the sum of the force exerted by the spring and damper is less than that of the impact force. Since the reaction force is not subject to the force utilized to accelerate the suspended mass, it observes a load less than that of the impact force. This is analogous to what is being measured by the impactor and reaction load cells. Since the effective mass of the femur and surrounding tissue is accelerated by the impactor, the force that the impactor load cell measures is necessarily larger than the sum of the reaction load cells. However, the force of real interest is the reaction load cell force. This gives an indication of the actual strength of the bone and its ability to resist failure.

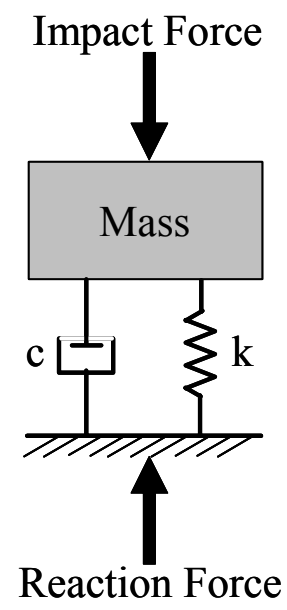

Figure 21: Spring-mass-damper model

In the ATD, because the femur load cell is located within the mid-shaft of the femur linkage, the load is already inertially compensated, given that it is not moving relative to the rest of the femur. The load that it measures is exactly that of the load transmitted to the femur, or $\mathrm{M}_{\mathrm{BEND}}$. For this reason, the load measured at the ATD's femur load cell is most comparable to 
the reaction load, not the impactor load, since the impactor load contains artifacts of inertial loads that are not seen by the reaction load cell. Therefore, the peak reaction moment, and not the peak impactor moment, is used in the survival analysis employed to determine injury risk functions for the femur.

The results from experimental testing and subsequent statistical analysis illustrate that there is no statistically significant difference between peak bending moment and loading direction. Therefore, it is possible to develop a single equation to predict femur fracture from loading from all directions. This allows for all tests to be jointly analyzed for development of a more precise model. It is recommended that this model be used to predict the risk of femur fracture by utilizing the resolved ATD femur moment, $\mathrm{M}_{\mathrm{X}}$ and $\mathrm{M}_{\mathrm{Y}}$ as measured by the mid-shaft femur load cell (Equation 13).

$$
\text { Resolved Femur Load Cell Moment }\left(\mathrm{M}_{\mathrm{RESOLVED}}\right)=\sqrt{{M_{X}{ }^{2}+M_{Y}{ }^{2}}^{2}}
$$

\section{Elasticity Calculations}

The beam formula for linear elastic behavior is used to calculate the stress for all tested specimens. While this method allows a good method of comparison between the response and ultimate strength of various biologic tissues, the assumption that the material in question behaves as a linear elastic material can be misleading. It has been shown that bone displays plasticity effects at high strain (Burstein et al. 1972, Reilly and Burstein 1974, Fondrk et al. 1988, Fondrk et al. 1999, Neibur et al. 2000, Turner and Burr 2001). The effects of plasticity result in the material failing at a lower ultimate stress than predicted by application of a purely elastic beam formula. For example, for a solid specimen of circular cross-section, the stress predicted by the beam formula for linear elastic behavior will overestimate the actual yield strength of the 
material by up to 221 percent of the actual yield strength of the material (Burstein et al. 1972). Therefore, it can be considered that the failure stresses calculated in this study are to be considered maximums, and that the actual failure stresses are lower than predicted here. The average failure stress observed in this study, $202.8 \mathrm{MPa}$, is overestimated when compared to the $185 \mathrm{MPa}$ failure stress determined from research performed on cortical bone at comparable strain rates (Wright and Hayes 1976). Likewise, the modulus of elasticity calculated from this data is stiffer compared to other research on cortical bone under bending loads. The average modulus of elasticity determined from this study is $16.60 \mathrm{GPa}$, compared with a published range of $9.1 \mathrm{GPa}$ to 15.7 GPa from other studies (Sedlin and Hirsch 1966, Keller et al. 1990, Lotz et al. 1991, Curry et al. 1997). However, the modulus calculated in this study is based upon dynamic bending tests, whereas the modulus previously reported in other literature was based upon quasistatic testing conditions. It is expected for dynamic tests that the bone will display a higher stiffness value than under quasistatic tests, so it is reasonable to expect a slightly higher modulus such as that measured in these dynamic tests.

To properly characterize the material properties of the femur, including plasticity effects, was not the goal of this study. The intent of being able to predict the functional failure of bone with the use of an injury risk function does not rely on the development of material properties of femur cortical bone. If true material failure is desired, rather than functional failure, a different methodology must be employed, requiring small coupon testing of bone to determine the level of plasticity and other properties (Turner and Burr 2001). This is out of the scope of the current study but would be useful from a biomechanical material property standpoint. 
No statistical analysis is performed on the results of the calculated stress or modulus of elasticity of the specimens. This is because the assumption of linear elasticity is employed to generate these values. Since bone is known to exhibit a more complex behavior than linear elastic, statistical characterization of these values would be misleading.

Stress and strain data are used from each experiment to calculate the elastic modulus of the specimens. The strain data used is taken from the in situ strain gage. The gage was mounted in accordance with accepted practices the same fashion as previous studies (Duma 1998, Duma 1999), and a methodology provided by Fritton and Rubin (2001); therefore, the gage is not expected to have compromised the validity of the measurements.

\section{Statistical Analysis Implications}

The test of goodness of fit of experimental data to a Weibull-based survival analysis is a plot of natural $\log$ of the negative natural $\log$ of the survival function versus the natural $\log$ of the peak reaction moment (Figure 22). With a Weibull-based injury risk function, the resultant plot should be linear to indicate a good fit (Cantor 1997). The resulting plot of all experimental data

points shows an $\mathrm{R}^{2}$ value of 0.97 for a linear fit, indicating the suitability of the Weibull model for the experimental data collected. 


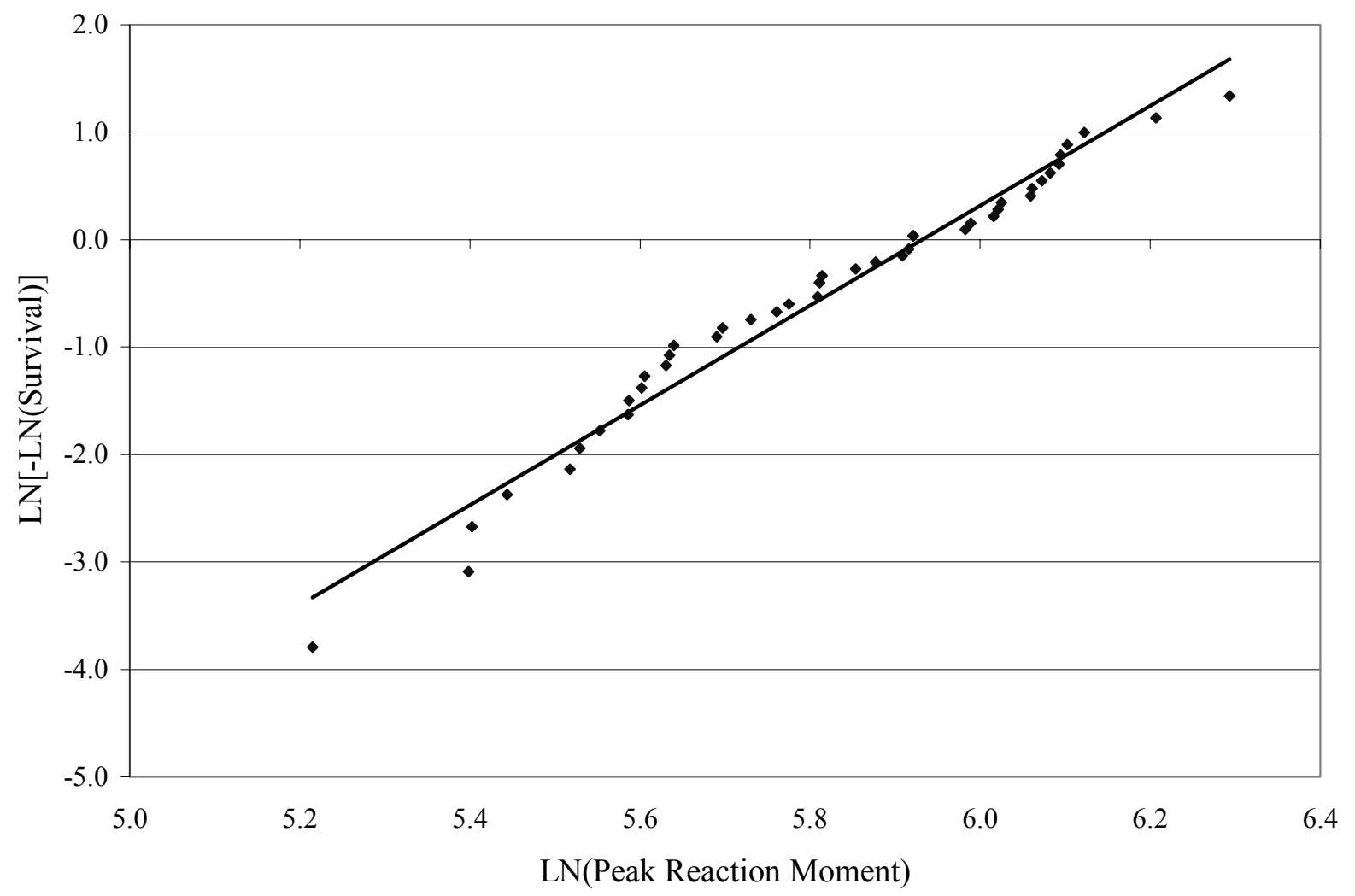

Figure 22: Verification of suitability of Weibull model to explain experimental data.

Statistical analysis of the data shows the variables, area, mass, inertia, $c, I / c$, and gender, are significant in predicting femur fracture. Additionally, it is shown that area, mass, inertia, $c$, $I / c$, and gender are correlated with one another. This is expected since, for example, females are less massive and have smaller cross-sectional area of bones than males, and as area increases for a consistent geometry so does inertia. The reason that one variable can be used to adequately predict the risk of fracture is due to the high correlation between the variables. For example, the correlation is strong enough so that when cross-sectional area is measured and used to predict peak moment, no other variables are significant.

In a similar manner as the present study, previous researchers have found bone crosssectional area to be a significant predictor of bone fracture (Bass et al. 1997, Wapnairz et al. 
1997, Myburgh et al. 1992). While these studies were performed on the forearm, they investigated the correlation of several geometric and material parameters on fracture tolerance. It is determined that area and moment of inertia of the bone are more important than bone mineral density in predicting ultimate fracture strength. This is true because bone mineral density, as determined by methods such as a QCT scan, is a local assessment of the mineral content of a given volume of bone (Kaufman and Siffert 2001). The actual density of bone does not change substantially with age or when affected by osteoporosis (Lundon et al. 1994, Boskey 2001). What is affected is the amount of bone present within the given cross-section (Webster 2001). It is because of this loss of bone without a corresponding loss of the density of bone, that a correlation is not seen in this study between bone mineral density and cross-sectional area or I/c (Figure 16 and Figure 18). Other studies have shown that the best predictors of fracture involve a strength index, which accounts for bone cross-sectional area in addition to bone mineral density (Ahlborg et al. 2003). The determination that cross-sectional area is better correlated than bone mineral density to failure strength of bone is consistent with the former studies, and the range of bone mineral density in this study from 968 to $1239 \mathrm{mg} / \mathrm{cm}^{3}$ is consistent with that found by other researchers (Sievanen et al. 1998). Therefore, the current study suggests that cross-sectional area of bone is more important than the bone mineral density for evaluating the strength of long bones and the risk of fracture.

Since it is found that cross-sectional area is most significantly related to fracture due to femur bending, a risk function is developed that utilized the variable of area (Equation 10). The Weibull model may be interpreted in terms of a baseline risk model that involves only peak moment. This model is then altered or, in survival analysis terminology, accelerated by the regression variable, in this case area. The size of the coefficient $\left(\beta_{1}\right)$ indicates the degree of 
alteration, and the sign indicates the direction of the alteration, with a positive sign indicating reduction in risk. Thus the positive sign associated with area indicates that an increase in area results in reduced risk. The size of the coefficient is difficult to interpret, although the significance $(p=0.0001)$ of the test indicates the importance of cross-sectional area with respect to bending strength of the femur (Table 9).

Geometric parameters such as cross-sectional area and $I / c$ of the mid-shaft femur are not easily obtainable for each vehicle occupant; however, the geometric properties of the mid-shaft femur were estimated for the $5^{\text {th }}, 50^{\text {th }}$, and $95^{\text {th }}$ percentiles for males and females by performing an empirical distribution analysis for data collected from each test specimen. Geometric values of cross-sectional area and $I / c$ were sorted by gender, and the data is used to create a distribution curve for these values within the male and female population segments. From these distribution curves, values for cross-sectional area and $I / c$ can be estimated at the $5^{\text {th }}, 50^{\text {th }}$, and $95^{\text {th }}$ percentiles. Given the large sample size of this study, and since no geometric constraint was placed upon the cadavers during cadaver selection, these values for cross-sectional area and $I / c$ values for population percentiles should be accurate estimates for the adult population.

\section{Injury Risk Curve Comparison}

The three injury risk functions predict a 50 percent risk of fracture at different peak moments depending on the variables used (Table 10). Area and $I / c$ are shown to be correlated with each other and are two of the most highly correlated variables to peak reaction moment

(Table 6 and Table 7). As such, both yield similar results for 50 percent risk of the $5^{\text {th }}, 50^{\text {th }}$, and $95^{\text {th }}$ percentiles. When compared to the area- and $I / c$-based risk functions, the gender- and mass- 
based function predicts a lower moment for 50 percent risk to the $95^{\text {th }}$ percentile male, but predicts a higher moment for 50 percent risk to both the $50^{\text {th }}$ male and $5^{\text {th }}$ percentile female.

Table 10: 50 percent risk of femur fracture due to injury risk curves using variables of area, $I / c$, and gender and mass.

\begin{tabular}{|l|c|c|c|}
\hline \multicolumn{1}{|c|}{ ATD } & Area & $I / c$ & Gender and mass \\
\hline $5^{\text {th }_{0}} \%$ Female & $240 \mathrm{Nm}$ & $260 \mathrm{Nm}$ & $274 \mathrm{Nm}$ \\
\hline $50^{\text {th }_{\%}}$ Male & $395 \mathrm{Nm}$ & $390 \mathrm{Nm}$ & $402 \mathrm{Nm}$ \\
\hline $95^{\text {th }_{\%}}$ Male & $562 \mathrm{Nm}$ & $551 \mathrm{Nm}$ & $420 \mathrm{Nm}$ \\
\hline
\end{tabular}

The gender- and mass-based risk function weighs the influence of gender more heavily than that of mass, with a coefficient of 1.9657 compared to 0.0137 (Equation 12). Therefore, moment values that predict a 50 percent risk of fracture are very similar for the $50^{\text {th }}$ and $95^{\text {th }}$ percentile males, at $402 \mathrm{Nm}$ and $420 \mathrm{Nm}$ respectively, an increase of 5 percent. Meanwhile, for 50 percent risk of fracture, the cross-sectional area-based prediction of bending strength increases by 42 percent and the $I / c$-based prediction increases by 51 percent over the same population subsets.

Cross-sectional area has been found to be most highly correlated $\left(\mathrm{R}^{2}=0.77\right)$ and significant variable $(\mathrm{p}=0.0001)$ in regard to correlation with peak bending moment. Therefore, the most appropriate risk function to use when predicting likelihood of femur fracture due to bending is the risk function that utilizes the variable area. While other risk functions may be more practically useful, for instance the mass- and gender-based model can easily generate a risk curve for a person of a given stature without having to estimate the cross-sectional area or $I / c$ of that person, the most accurate predictor of injury risk was found to be cross-sectional area. Therefore, it is the risk function containing the variable area that should be used for application with ATDs and computational models for determining risk of femur fracture. 


\section{Previous Experimental Findings}

The results of this study are not similar to the results of the previous quasistatic bending tests. Weber (1859) and Messerer (1880) reported maximum bending moments for female subjects of $182 \mathrm{Nm}$ and $180 \mathrm{Nm}$, respectively, and for male subjects of $233 \mathrm{Nm}$ and $310 \mathrm{Nm}$, respectively. Data from this study show that the maximum bending moment for females is $286 \pm$ $50 \mathrm{Nm}$ and for males is $401 \pm 78 \mathrm{Nm}$. Overall, this study finds a maximum bending moment of $350 \pm 88$ Nm compared to Motoshima's 165 Nm (1960) and Stromsoe's 181 Nm (1995). These differences are to be expected, given the viscoelastic behavior of bone and the dramatically different loading rates employed in these tests. For accurate prediction of bone response given high rate loading conditions, it is therefore necessary to utilize data from test specimens at the loading rate in question.

However, the results obtained from this experiment are comparable to those obtained from previous dynamic research. The bending moment at failure for the posterior loading condition is $348 \pm 96 \mathrm{Nm}$. Likewise, the lateral loading condition yields similar results at $352 \pm$ $83 \mathrm{Nm}$. Overall, the average bending moment and standard deviation for these tests is $350 \pm 88$ Nm. These values compare favorably with those obtained by Martens et al. (1986) and Kerrigan et al. (2003), who measured the ultimate bending moment of the femur at $373 \pm 84 \mathrm{Nm}$ and 412 $\pm 114 \mathrm{Nm}$, respectively.

Though it is impossible to compare the data of this test with that observed by Matsui et al. (2004), it is useful to look at their results. Since much of the impact force seen in Matsui et al.'s tests went into the inertial response of the lower leg, it would be impossible to determine the bending stiffness of the femur from their data. It does offer validation; however, for the 
utilization of a femur bending test to determine the bending strength of the femur, since the observed fractures were indicative of failure due to bending.

\section{Subject Age Effects}

Previous researchers have found age to be a significant factor for lower extremity injury prediction (Funk et al. 2002). Although the present study does not find age to be statistically significant, the p-values are low with a p-value of 0.1423 from the mixed model regression and a p-value of 0.0579 using the more accurate bootstrap analysis which accounts for multiple samples from the same cadaver. The range of ages used in the Funk study was 40 years to 75 years, whereas in the present study of femur tolerance the age range of available samples is 49 years to 83 years. The range of ages available for testing in this study was small, unfortunately precluding a statistically significant analysis of the effects of age.

The age range of available donors for this study was limited with only 5 specimens tested that were from donors that were younger than 57 or older than 74 years of age. Primarily excluded from this study, solely due to the availability of tissue, was the younger segment of the population. Since it has been shown that bone weakens with age (Lindahl and Lindgren 1967, Burstein et al. 1976, Martin and Burr 1989), the current study does not have the capability of evaluating injury potential in the younger population.

\section{Limitations}

In order to perform testing with the capability of statistically detecting differences in varying loading orientations and given the number of test specimens available, the testing was only performed in the lateral-to-medial and posterior-to-anterior loading directions. It is 
desirable for future testing to test specimens in additional loading orientations and characterize the response of the femur in alternative directions for comparison to the results of this testing.

As previously noted, it is desirable that additional tests be performed with a larger range of donor ages, to correlate age with the peak failure moment observed in these tests. Also, though it was out of the scope of this study, the effects of plasticity with respect to the femur should be determined for better understanding of the localized material response and actual failure stresses observed within the femur. 


\section{CONCLUSION}

A total of 45 experiments were performed on human cadaver femurs using a dynamic three-point drop test setup. Test specimens were impacted in the lateral-medial and posterioranterior directions. Both impactor and reaction moments were calculated from measured experimental data; however, due to inertial effects, the average peak impactor moment measured 14 percent higher than the average peak reaction moment. The reaction loads were used to develop the injury criteria given that they represent the inertially compensated bending strength of the femur that is more appropriate for dummy load cell application. No significant $(\mathrm{p}=$ 0.7856) difference was found between the lateral-medial and posterior-anterior bending tests. Data from the in situ strain gage indicate that the average strain at failure was $1.2 \pm 0.3$ percent. Also, it has been shown that quasistatic loading tests will underestimate the dynamic bending strength of the human femur.

Injury risk functions were presented for predicting femur fracture due to dynamic bending. Risk functions have been developed using both localized descriptors to describe femur strength and global predictors used to predict femur strength. The cross-sectional area and geometric descriptor, $I / c$, of the femur were significant factors in determining the failure strength of the femur, while bone mineral density was not. Risk functions have been presented that utilize peak bending moment and area, or peak bending moment and $I / c$ as a predictor of risk of femur fracture. A three variable risk function that uses peak bending moment, gender and mass was also presented. The risk function that utilizes the most highly correlated $\left(\mathrm{R}^{2}=0.77\right)$ and significant $(\mathrm{p}=0.0001)$ variable, cross-sectional area, predicts a 50 percent risk of femur fracture of $240 \mathrm{Nm}, 395 \mathrm{Nm}$, and $562 \mathrm{Nm}$ for equivalent cross-sectional area of the $5^{\text {th }}$ percentile female, $50^{\text {th }}$ percentile male, and $95^{\text {th }}$ percentile male respectively. 


\section{REFERENCES}

American Association for Automotive Medicine (AAAM). (1990) Abbreviated Injury Scale (AIS) - 1990 Revision. American Association for Automotive Medicine, Morton Grove, IL.

Ahlborg, H.G., Johnell, O., Turner, C.H., Rannevik, G., and Karlsson, M.K. (2003) Bone loss and bone size after menopause. New England Journal of Medicine 349(4): 327-334.

Bass, C.R., Duma, S.M., Crandall, J.R., Morris, R., Martin, P., Pilkey, W.D., Hurwitz, S., Nhaewpong, N., Eppinger, R., and Sun, E. (1997) The interaction of air bags with upper extremities. Stapp Car Crash Journal 41: 111-129. SAE 973324.

Boskey, A.L. (2001) Bone mineralization. In Bone Biomechanics Handbook, Second Edition, ed. S.C. Cowin, pp. 5-1 to 5-33. CRC Press, Washington D.C.

Burstein, A.H., Currey, J.D., Frankel, V.H., and Reilly, D.T. (1972) The ultimate properties of bone tissue: the effects of yielding. Journal of Biomechanics 5: 35-44.

Burstein, A.H., Reilly, D.T., and Martens, M. (1976) Aging of bone tissue: Mechanical properties. Journal of Bone and Joint Surgery 58A(1): 82-86.

Cantor, P. (1997) Extending the SAS survival analysis techniques for medical research. SAS Institute, Cary, NC.

Collett, D. (1999) Modeling survival data in medical research. Chapman and Hall, London.

Cristofolini, L., Viceconti, M., Cappello, A., and Toni, A. (1996) Mechanical validation of whole bone composite femur models. Journal of Biomechanics 29(4): 525-535.

Currey, J.D., Foreman, J., Laketic, I., Mitchell, J., Pegg, D.E., and Reilly, G.C. (1997) Effects of ionizing radiation on the mechanical properties of human bone. Journal of Orthopaedic Research 15(1): 111-117.

Dischinger, P.C., Burgess, A.R., Cushing, B.M., Pilkey, W.D., Crandall, J.R., Sieveka, E.M., and Klopp G.S. (1994) Lower extremity trauma in vehicular front-seat occupant. SAE 940710.

Duma, S.M., Crandall, J.R., Hurwitz, S.R., and Pilkey, W.D. (1998) Small female upper extremity interaction with a deploying side air bag. Stapp Car Crash Journal 42. SAE 983148.

Duma, S.M., Schreiber, P.H., McMaster, J.D., Crandall, J.R., Bass, C.R., and Pilkey, W.D. (1999) Dynamic injury tolerances for long bones of the female upper extremity. Journal of Anatomy 194: 463-471.

European Enhanced Vehicle-Safety Committee. (2002) EEVC working group 17 report: Improved test methods to evaluate pedestrian protection afforded by passenger cars. 
Federal Motor Vehicle Safety Standards. Standard number 208: Occupant crash protection. U.S. Department of Transportation National Highway Traffic Safety Administration.

Fondrk, M.T., Bahniuk, E.H., Davy, D.T., and Michaels, C. (1988) Some viscoplastic characteristics of bovine and human cortical bone. Journal of Biomechanics 21(8): 623-630.

Fondrk, M.T., Bahniuk, E.H., and Davy, D.T. (1999) Inelastic strain accumulation in cortical bone during rapid transient tensile loading. Journal of Biomechanical Engineering 121(6): 616-621.

Fritton, S.P., and Rubin, C.T. (2001) In vivo measurement of bone deformations using strain gages. In Bone Biomechanics Handbook, Second Edition, ed. S.C. Cowin, pp. 8-1 to 8-41. CRC Press, Washington D.C.

Funk, J.R., Srinivasan, C.M., Crandall, J.R., Khaewpong, N., Eppinger, R.H., Jaffredo, A.S., Potier, P., and Petit, P.Y. (2002) The effects of axial preload and dorsiflexion on the tolerance of the ankle/subtalar joint to dynamic inversion and eversion. Stapp Car Crash Journal 46: 245-265. SAE 2002-22-0013.

Isenberg, R.A., Walz, M., Chidester, C., and Kaufman, R. (1996) Pedestrian crash data study An interim evaluation. Proceedings of the $15^{\text {th }}$ International Technical Conference on Enhanced Safety of Vehicles: 1396-1407.

Kaufman, J.J. and Siffert, R.S. (2001) Noninvasive measurement of bone integrity. In Bone Biomechanics Handbook, Second Edition, ed. S.C. Cowin, pp. 34-1 to 34-25. CRC Press, Washington D.C.

Keller, T.S., Mao, Z., and Spengler, D.M. (1990) Young's modulus, bending strength, and tissue physical properties of human compact bone. Journal of Orthopaedic Research 8: 592-603.

Kerrigan, J.R., Bhalla, K.S., Madeley, N.J., Funk, J.R., Bose, D., and Crandall, J.R. (2003) Experiments for establishing pedestrian-impact lower limb injury criteria. SAE 2003-010895.

Kress, T.A. and Porta, D.J. (2001) Characterization of leg injuries from motor vehicle impacts. Proceedings of the 17th International Technical Conference on the Enhanced Safety of Vehicles. ESV Paper 443.

Levine, R.S. (2002) Injury to the extremities. In Accidental Injury: Biomechanics and Prevention, ed. A.M. Nahum and J.W. Melvin, pp. 491-522. Springer-Verlag, New York.

Lindahl, O., and Lindgren, A.G. (1967) Cortical bone in man, II. Variation in tensile strength with age and sex. Acta Orthopaedica Scandinavica 38: 141-147. 
Littell, R.C., Milliken, G.A., Stroup, W.W., and Wolfinger, R.D. (1996) SAS system for mixed models. SAS Institute, Cary, NC.

Lotz, J.C., Gerhart, T.N., and Hayes, W.C. (1991) Mechanical properties of metaphyseal bone in the proximal femur. Journal of Biomechanics 24: 317-329.

Lundon, K., Dumitriu, M., and Grynpas, M. (1994) The long-term effect of ovariectomy on the quality and quantity of cancellous bone in young macaques. Bone and Mineral 24(2): 135149.

Martens, M., van Audekercke, R., de Meester, P., and Mulier, J.C. (1986) Mechanical behavior of femoral bones in bending load. Journal of Biomechanics 19(6): 443-454.

Martin, R.B., and Burr, D.B. (1989) Structure, function, and adaptation of compact bone. Raven Press, New York.

Mather, B.S. (1967) Correlations between strength and other properties of long bones. Journal of Trauma 7(5): 633-638.

Mather, B.S. (1968a) Observations on the effects of static and impact loading on the human femur. Journal of Biomechanics 1(1): 331-335.

Mather, B.S. (1968b) Variation with age and sex in strength of the femur. Medical and Biological Engineering 6: 129-132.

Matsui, Y., Schroeder, G., and Bosch, U. (2004) Injury pattern and response of human thigh under lateral loading simulating car-pedestrian impact. SAE 2004-01-1603.

McElhaney, J.H., Roberts, V.L., and Hilliard, J.F. (1976) Handbook of human tolerance. Japan Automobile Research Institute.

Messerer, O. (1880) Uber elasticitat and festigkeit der menschlichen knochen. J.G. Cotta, Stuttgart.

Montgomery, D.C. (1996) Introduction to statistical quality control. John Wiley and Sons, New York.

Morgan, R.M., Eppinger, R.H., and Hennessey, B.C. (1991) Ankle joint injury mechanism for adults in frontal automotive impact. Stapp Car Crash Journal 35. SAE 912902.

Motoshima, T. (1960) Studies on the strength for bending of human long extremity bones. Journal of Kyoto Pref. Med. Univ. 68: 1377-1397.

Myburgh, K., Zhou, L., Steele, C., Arnaud, S., and Marcus, R. (1992) In vivo assessment of forearm bone mass and ulnar bending stiffness in healthy men. Journal of Bone and Mineral Research 7(11): 1345-1350. 
NASA. (1978) Anthropometric source book. Vols. I, II, and III: Anthropometry for designers. NASA Reference Publication 1024.

NHTSA. (2001) Traffic safety facts 2001: A compilation of motor vehicle crash data from the fatality analysis reporting system and the general estimates system. U.S. Department of Transportation National Highway Traffic Safety Administration, Washington, D.C.

Niebur, G.L., Feldstein, M.J., Yuen, J.C., Chen, T.J., and Keaveny, T.M. (2000) High-resolution finite element models with tissue strength asymmetry accurately predict failure of trabecular bone. Journal of Biomechanics 33: 1575-1583.

Nyquist, G.W. (1986) Injury tolerance characteristics of the adult human lower extremities under static and dynamic loading. Society of Automotive Engineers, SAE 861925.

Pattimore, D., Ward, E., Thomas, P., and Bradford M. (1991) The nature and cause of lower limb injuries in car crashes. Stapp Car Crash Journal 35. SAE 912901.

Reilly, D.T., and Burstein, A.H. (1974) The mechanical properties of cortical bone. Journal of Bone and Joint Surgery 56-A(5): 1001-1022.

Rupp, J.D., Reed, M.P., Van Ee, C.A., Kuppa, S., Wang, S.C., Goulet, J.A., and Schneider, L.W. (2002) The tolerance of the human hip to dynamic knee loading. Stapp Car Crash Journal 46. SAE 2002-22-0011.

Sakurai, M., Kobayashi, K., Ono, K., and Sasaki, A. (1994) Evaluation of pedestrian protection test procedure in Japan - Influence of upper body mass on leg impact test. Proceedings of the $14^{\text {th }}$ International Technical Conference on Enhanced Safety of Vehicles: 1114-1130. ESV Paper 94-S7-O-01.

SAS Institute, Inc. (1999) SAS/STAT user's guide, version 8, volume 2. SAS Institute, Inc., Cary, NC.

Sedlin, E.D., and Hirsch, C. (1966) Factors affecting the determination of the physical properties of femoral cortical bone. Acta Orthopaedica Scandinavica 37: 29-48.

Sievanen, H., Koskue, V., Rauhio, A., Kannus, P., Heinonen, A., and Vuori, I. (1998) Peripheral quantitative computed tomography in human long bones: Evaluation of in vitro and in vivo precision. Journal of Bone and Mineral Research 13(5): 871-872.

Society of Automotive Engineers. (1989) SAE J833 - Human physical dimensions, Recommended Practice.

Stromsoe, K., Hoiseth, A., Alho, A., and Kok, W.L. (1995) Bending strength of the femur in relation to non-invasive bone mineral assessment. Journal of Biomechanics 28(7): 857-861. 
Turner, C.H., and Burr, D.B. (2001) Experimental techniques for bone mechanics. In Bone Biomechanics Handbook, Second Edition, ed. S.C. Cowin, pp. 7-1 to 7-35. CRC Press, Washington D.C.

Van Ee, C.A., Chasse, A.L., and Myers, B.S. (1998) The effect of postmortem time and freezer storage on the mechanical properties of skeletal muscle. Stapp Car Crash Journal 42. SAE 983155.

Van Rooij, L., Bhalla, K., Meissner, M., Ivarsson, J., Crandall, J., Longhitano, D., Takahashi, Y., Dokko, Y., and Kikuchi, Y. (2003) Pedestrian crash reconstruction using multi-body modeling with geometrically detailed, validated vehicle models and advanced pedestrian injury criteria. Proceedings of the $15^{\text {th }}$ International Technical Conference on Enhanced Safety of Vehicles.

Wapnairz, M., Lehnamm, R., Reineke, M., Shonau, E., Klein, K., and Allolio, B. (1997) Determinants of radial bone density as measured by PQCT in pre- and postmenopausal women: The role of bone size. Journal of Bone and Mineral Research 2: 248.

Weber, C.O. (1859) Chirurgische erfahrungen and untersuchungen. Berlin (as cited by Messerer, 1880).

Webster, S.S. Jee. (2001) Integrated bone tissue physiology: anatomy and physiology. In Bone Biomechanics Handbook, Second Edition, ed. S.C. Cowin, pp. 1-1 to 1-68. CRC Press, Washington D.C.

Wright, T.M., and Hayes, W.C. (1976) Tensile testing of bone over a wide range of strain rates: Effects of strain rate, micro-structure and density. Medical and Biological Engineering and Computing 14: 671-680.

Yamada, H., and Evans, F.G. (1970) Strength of biological materials. Williams and Wilkins, Baltimore. 
APPENDIX A: Additional Statistical Analysis Plots

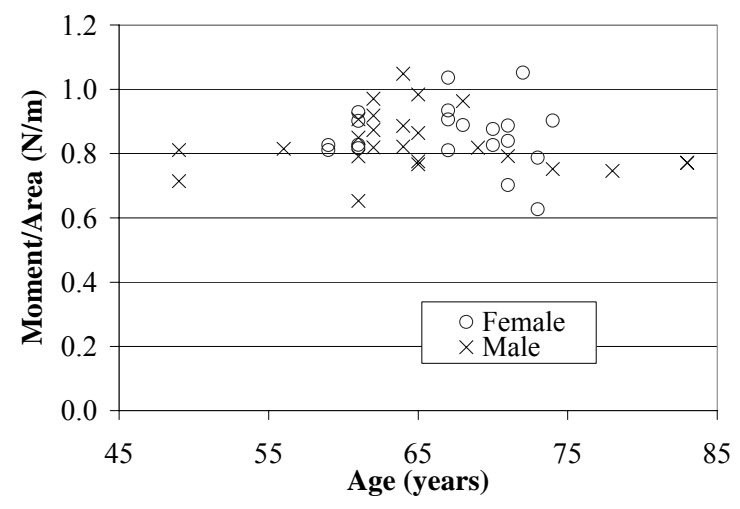

Figure A1: Bending moment normalized to cross-sectional area vs. age.

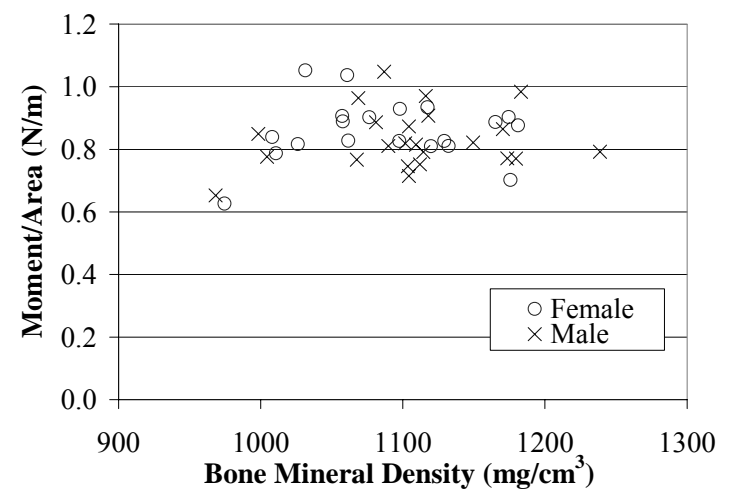

Figure A3: Bending moment normalized to cross-sectional area vs. bone mineral density.

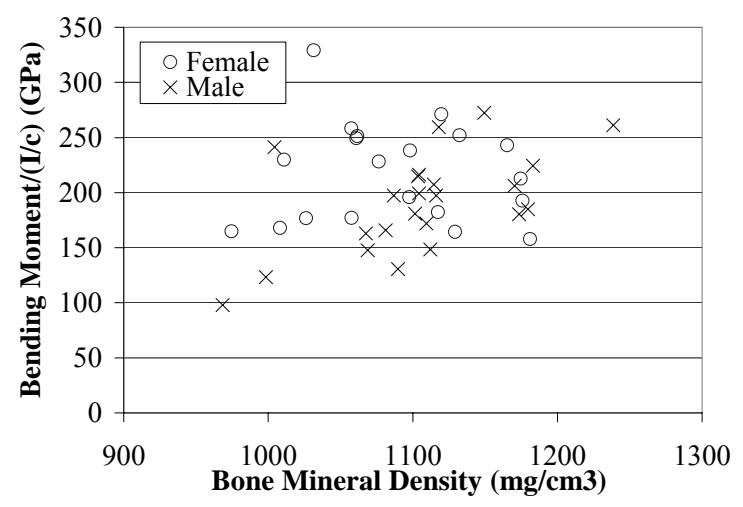

Figure A5: Bending moment normalized to $I / c$ vs. bone mineral density.

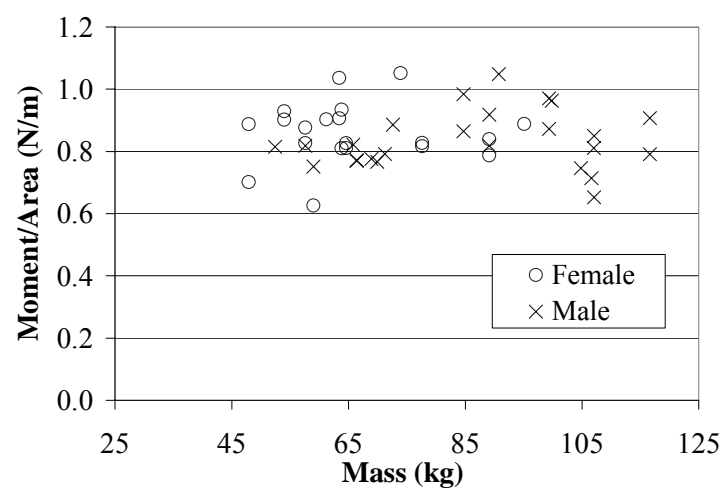

Figure A2: Bending moment normalized to cross-sectional area vs. mass.

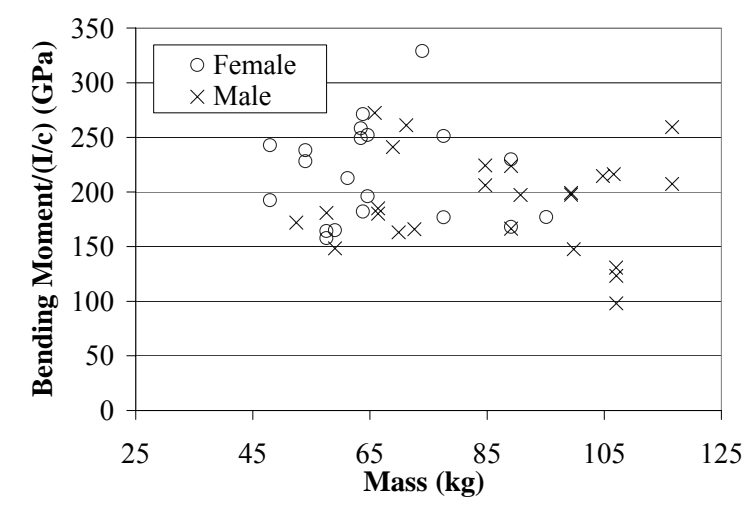

Figure A4: Bending moment normalized to $I / c$ vs. mass. 
APPENDIX B: Additional Statistical Analysis Plots

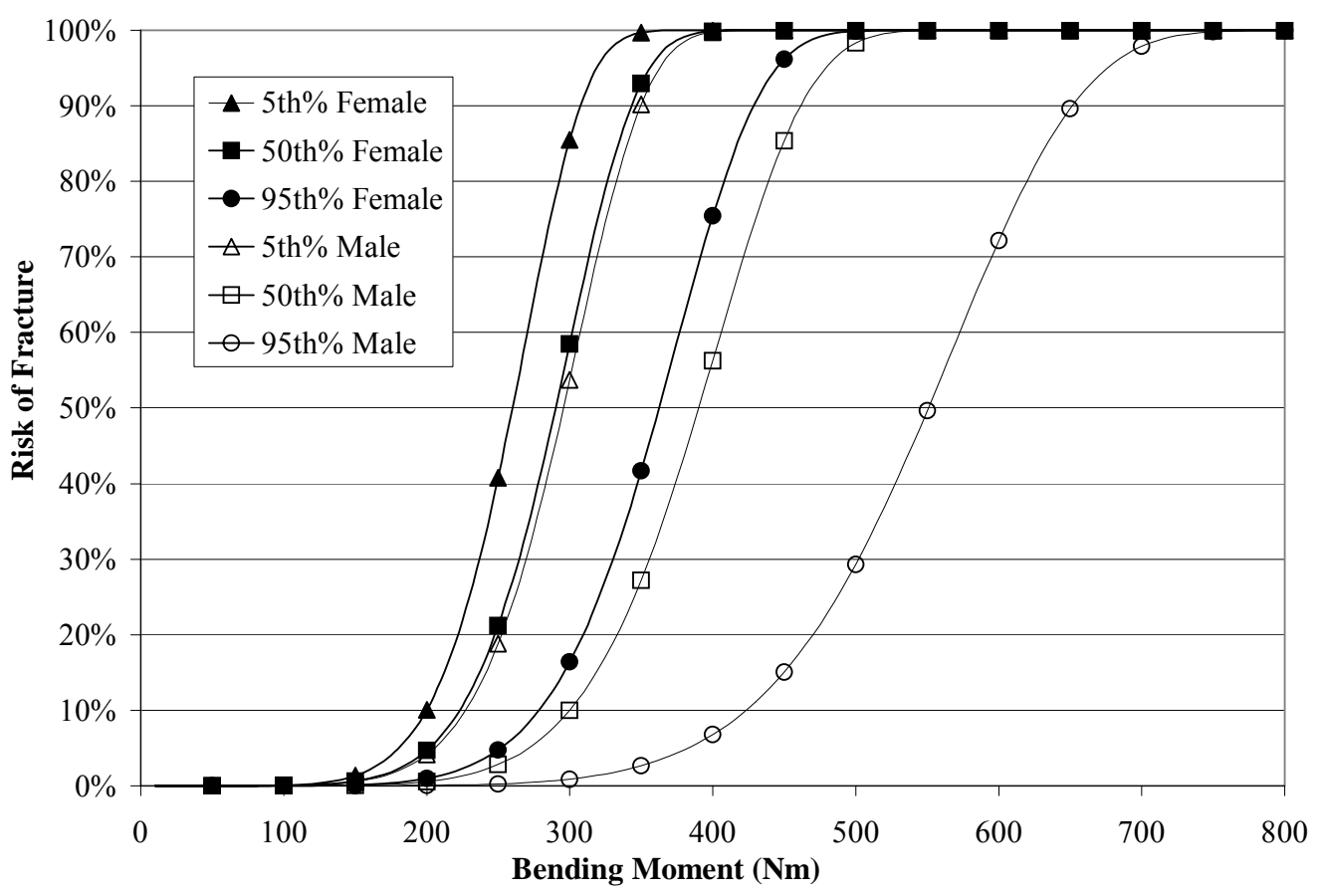

Figure B1: Femur fracture risk curves based on moment and mid-shaft femur $I / c$, geometric variable $I / c$ is estimated by empirical distribution of specimen data.

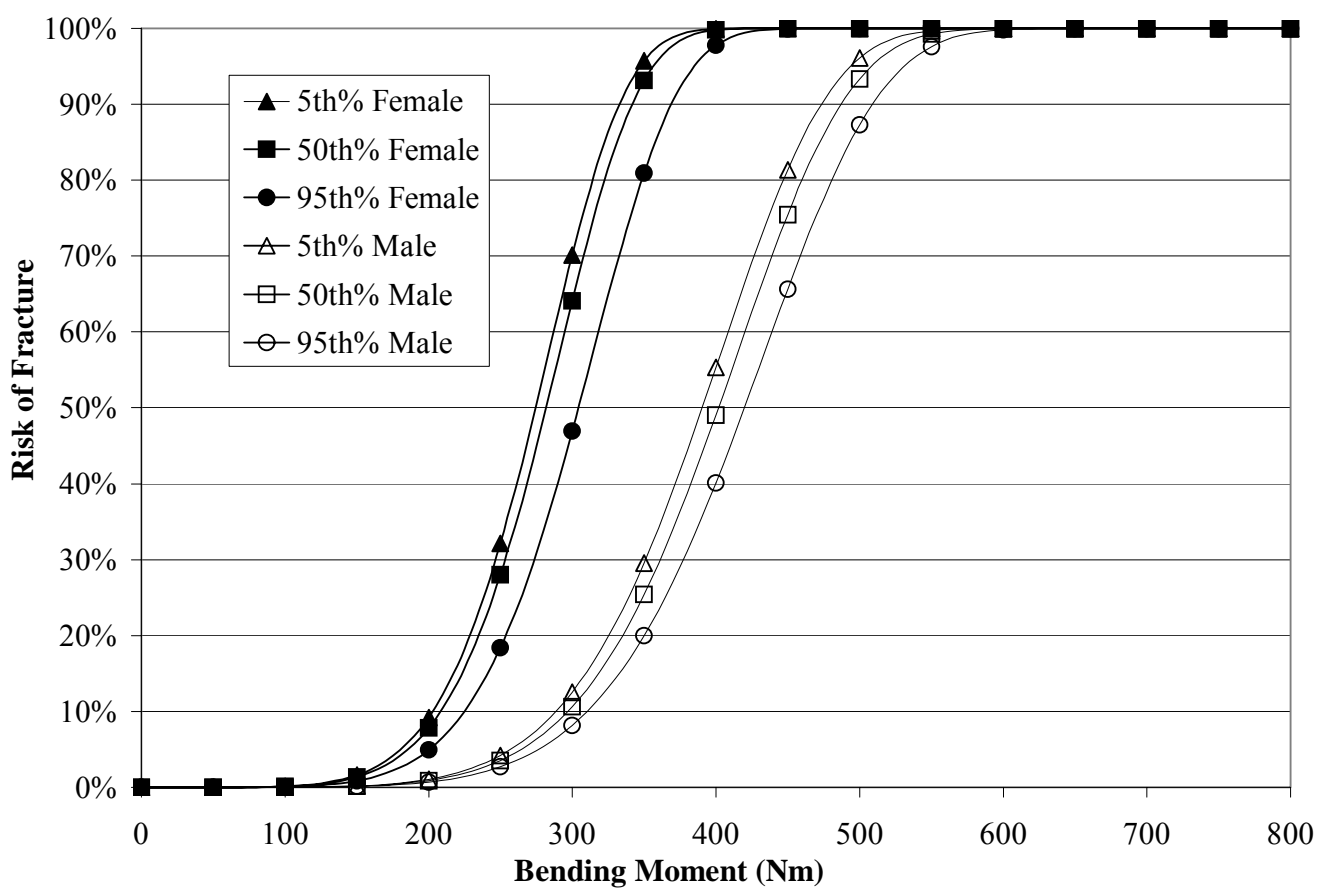

Figure B2: Femur fracture risk curves based on moment, gender, and occupant mass, values for mass from NASA and SAE guidelines for ATDs and general population (NASA 1978; SAE 1989). 


\section{VITA}

Eric Kennedy was born and raised in Westminster, Maryland. He reached the pinnacle of his success at an early age when he appeared on the children's television show "Romper Room" and knew that he had a middle name in addition to his first and last names. Following his Romper Room stardom, he went on to graduate from Westminster High School in 1994 and attended the University of Maryland, College Park (2002 NCAA Men's Basketball National Champions, 2004 ACC Men's Basketball Tournament Champions). At the University of Maryland, Eric majored in Mechanical Engineering and, after two cooperative education stints at Tenneco Automotive, Walker Electronic Silencing, graduated in 1999. After graduation, Eric worked for Pratt and Whitney Aircraft Engines and the Northrop Grumman Corporation, Electronic Sensors and Systems Sector as a mechanical engineer. Returning to school to fulfill his ambition to become a college professor, Eric will continue his graduate work at Virginia Tech to earn his Ph.D. He currently lives in a house in the woods of Christiansburg, Virginia with his beloved dog, Schatzie. 